Portland State University

PDXScholar

Summer 7-31-2018

\title{
Human-Centered Design of an Air Quality Feedback System to Promote Healthy Cooking
}

Chantal Iribagiza

Portland State University

Follow this and additional works at: https://pdxscholar.library.pdx.edu/open_access_etds

Part of the Environmental Engineering Commons

Let us know how access to this document benefits you.

\section{Recommended Citation}

Iribagiza, Chantal, "Human-Centered Design of an Air Quality Feedback System to Promote Healthy Cooking" (2018). Dissertations and Theses. Paper 4547.

https://doi.org/10.15760/etd.6432

This Thesis is brought to you for free and open access. It has been accepted for inclusion in Dissertations and Theses by an authorized administrator of PDXScholar. Please contact us if we can make this document more accessible: pdxscholar@pdx.edu. 
Human-Centered Design of an Air Quality Feedback

System to Promote Healthy Cooking

by

Chantal Iribagiza

A thesis submitted in partial fulfillment of the requirements for the degree of

Master of Science

in

Civil and Environmental Engineering

Thesis Committee:

Evan Thomas, Chair

Scott Wells

Avinash Unnikrishnan

Portland State University

2018 
C) 2018 Chantal Iribagiza 


\begin{abstract}
Household air pollution (HAP) is responsible for almost 4 million premature deaths every year, a burden that is primarily carried by women and children in developing countries. The mortality and morbidity impact of HAP can be significantly alleviated through clean cookstove interventions. However, for these interventions to be effective, the new intervention stove must be a substantially cleaner technology and adoption should be high and sustained over time.

Woody biomass is the fuel of choice in many developing communities, and contributes substantially to HAP. Several organizations have launched clean cooking interventions to address this issue. However, the majority of those interventions do not address adoption related challenges, that they often face.

This thesis explores previous studies on Human-Centered Design (HCD) and the impact of feedback and data access on behavior change. It details a HCD process and methodology applied during the design process of an air quality feedback system, to improve adoption of liquefied petroleum gas (LPG) cookstoves in Rwanda. The feedback system is intended to provide real-time air quality information to stove users and potentially encourage them to abandon traditional biomass cookstoves in favor of the cleaner LPG stoves.
\end{abstract}




\section{Dedication}

Dedicated to my grandparents, in appreciation for their support of my academic

endeavors, for teaching me the ethics of hard work, being encouraging along the way and believing in me. 


\section{Acknowledgments}

First, I want to express my sincere gratitude to my academic advisor Dr. Evan Thomas, for providing me with guidance during not only the preparation of this thesis, but also during my journey as a master's student in the last two years. The skills and knowledge I have gained as a part of our research group, played a big role in making this thesis possible and in my other accomplishments as a graduate student.

Second, I appreciate the contributions from Taylor Sharpe and Dr. Daniel Wilson during designing and prototyping phases of the products discussed in this thesis. Many thanks to Taylor Sharpe and Pie Nkubito for their contributions during the HumanCentered Design process in Rwanda and materials preparation, field work and data consolidation. I appreciate the training and guidance on the Human-Centered Design process provided by Heather Fleming, of Catapult Design.

Last but not least, I want to convey my sincere thanks to my co-workers in the SWEETLab, for their valuable insights and feedback. 


\section{Table of Contents}

Abstract

Dedication $\quad$ ii

Acknowledgments $\quad$ iii

List of Tables vii

List of Figures viii

List of Abbreviations $\quad \mathrm{x}$

Chapter 1: Introduction 1

Chapter 2: Literature Review $\quad 4$

2.1. A silent killer: need for electronic monitoring of household air pollution 7

2.2. Behavior change: promotion, facilitation and monitoring 8

2.3. Feedback as a behavior change tool 11

$\begin{array}{ll}\text { Chapter 3: Study Context } & 14\end{array}$

3.1. The Household Air Pollution Intervention Network (HAPIN) Study 14

Chapter 4: Human-Centered Design Overview 16

Chapter 5: Methods 17

5.1. Study Objectives 17

$\begin{array}{lll}\text { 5.2. Participants selection process } & 18\end{array}$

$\begin{array}{lll}\text { 5.3. HCD Methodology } & 18\end{array}$ 
6.1. Cookstove technologies in the community

6.2. Study sample cooking habits

6.3. Stove-stacking

6.4. LPG cookstove exclusive use and perception

6.5. Colors and iconography

6.6. Identified clean cooking behavior change triggers

6.7. Air quality feedback delivery means

6.8. Peer discussion and group consensus through voting

8.5. Cost estimates 
9.3. Numerical Model with time variable emissions

9.4. Analytical Model with constant emissions

Chapter 10: Conclusion

Future work

Work Cited

Appendix A- Triggers identification cards

Appendix B- Feedback delivery means identification cards

Appendix C- Household interview questions

Appendix D- Summary household interview answers

66 


\section{List of Tables}

Table 1: Summary of cookstove technologies reported in the community

Table 2: Color perception reported by participants

Table 3: Experiment environment characteristics 


\section{List of Figures}

Figure 1: cause of deaths among children under the age of 5 in Rwanda (Institute for Health Metrics and Evaluation (ihme) 2015) 5

Figure 2: Stove-stacking, adapted from Ruiz-Mercado et al (2011) 9

Figure 3: Transition from tradition fuels to modern fuels and staking of fuels.

$\begin{array}{ll}\text { Adapted from Yadama (2013) } & 10\end{array}$

Figure 4: HCD process work in Rwanda $\quad 19$

Figure 5: Example cards, depicting children's health and smoke, as one potential behavior change trigger that may influence LPG cookstove high adoption and $\begin{array}{ll}\text { exclusive use } & 21\end{array}$

Figure 6: Stove technologies use reported by study participants 26

Figure 7: Stove-stacking patterns reported by participants 26

Figure 8: Behavior change triggers in order of significance 30

Figure 9: Feedback delivery means in order of participants' preference 31

Figure 10: Air quality feedback system prototypes 36

Figure 11: The final product (audio-visual air quality feedback system) 38

Figure 12: Cost estimates for a unit feedback system (Estimates by Dr. Danny

Wilson)

Figure 13: Experimental Fume Hood Diagram $\quad 41$

Figure 14: Experiment environment. Fume hood with EcoZoom stove (left) and $\begin{array}{ll}\text { particle monitor (right) } & 42\end{array}$

Figure 15: Experiment in progress $\quad 43$

viii 
Figure 16: PM2.5 concentration in the fume hood over 4 hours and 11 minutes of running experiment

Figure 17: Modeled time variable emissions over time 45

Figure 18: Modeled $\mathrm{PM}_{2.5}$ concentration over time 46

Figure 19: Fitting of analytical model to experimental data 47

Figure 20: $\mathrm{PM}_{2.5}$ concentration modeling under recommended ventilation conditions 


\section{List of Abbreviations}

$\begin{array}{ll}\text { HAP } & \text { Household Air Pollution } \\ \text { HAPIN } & \text { Household Air Pollution Intervention Network } \\ \text { HCD } & \text { Human-Centered Design } \\ \text { LPG } & \text { Liquefied Petroleum Gas } \\ \text { LRI } & \text { Lower Respiratory Infections } \\ \text { NAAQS } & \text { National Ambient Air Quality Standards } \\ \text { PM } & \text { Particulate Matter } \\ \text { PM } & \\ \text { SMS } & \text { Particulate Matter of } 2.5 \text { microns diameter size or less } \\ \text { WHO } & \text { Short Message Service }\end{array}$




\section{Chapter 1: Introduction}

Human exposure to air pollutants can have adverse health effects that include respiratory irritations, pulmonary and cardiovascular diseases (Pope et al. 2002; Brunekreef and Holgate 2002), cancers and nervous system impairments (Genc et al. 2012). Household air pollution (HAP) may pose an even greater danger than ambient outdoor air pollution, especially among at-risk populations such as children and pregnant women because in addition to having a higher physiological susceptibility to air pollutants, they also tend to spend more time indoors than other people (Pickett and Bell 2011). Recent studies have linked air pollution to neurological diseases and neuropathology. Children chronically exposed to ozone and fine particulate matter levels higher than the current United States' National Ambient Air Quality Standards (NAAQS) presented health issues including neurovascular unit damage, diffuse neuroinflammation and production of neuro-antibodies (Calderón-Garcidueñas et al. 2016).

People living in developing nations have a higher exposure level to HAP than those living in higher income countries. Legros et al.'s “The Energy Access Situation in Developing Countries: A Review Focusing on the Least Developed Countries and SubSaharan Africa" published in 2009 (and cited in Yadama 2013) suggest that over 99\% of the year 2015 HAP related deaths occurred in low and middle-income countries. Landrigan et al (2018), using the World Bank data on development indicators, support this argument.

Studies suggest that approximately half the world's population (around 3 billion people), all of them residing in low and middle-income countries, depend on solid fuels 
for household energy needs, with $90 \%$ of them relying specifically on biomass burning for cooking and heating (Yadama 2013; Rehfuess, Mehta, and Prüss-Ustün 2006; Bruce, Perez-Padilla, and Albalak 2000). Biomass is burnt in open fire stoves with incomplete combustion, resulting in women and young children's daily exposure to toxic air pollutants (Bruce, Perez-Padilla, and Albalak 2000). Globally, cookstove smoke kills 4 million people every year, making HAP the fourth leading cause of death (Yadama 2013). This daily dependence on solid fuels results in an estimated 2.8 billion people exposure to HAP (Bonjour et al. 2013) and an estimated loss of around $0.58 \%$ of gross domestic product in low income countries (Landrigan et al. 2018).

HAP mortality and morbidity impacts can be significantly alleviated through clean cooking interventions. However, for these interventions to be effective, the new intervention technology must be substantially cleaner and its adoption must be high and sustained over time (Ruiz-Mercado et al. 2011). The majority of existing clean cooking interventions report adoption challenges, mainly stove-stacking, defined as "using multiple stoves and fuels" (Rosenthal et al. 2017), that undermine their ability to deliver the expected positive health outcomes. Stove-stacking happens when polluting traditional stoves are used in tandem with improved intervention stoves, and it is discussed in depth in section 2.2.

Rosenthal et al. (2017) outline dominant factors that influence clean cooking adoption, including availability and affordability of fuel, social status and safety concerns of the new technology, household characteristics, ease of use, cooking preferences among others and argues that a methodical design of the program, taking into account these 
factors and others, is needed for implementation success and sustainability of cookstove interventions. These reasons were this thesis' motivation, to consult with potential clean cooking intervention households, and develop a potential solution to tackle stovestacking, by encouraging them to abandon traditional polluting stoves in favor of the cleaner intervention stove.

Lessons learnt from previous and current cookstove interventions show that women's inclusion in decision making is of paramount importance when it comes to cookstove adoption rates (El Tayeb Muneer and Mukhtar Mohamed 2003). These lessons also showcase the need for a wide variety of professional disciplines and organizations involvement in the work to tackle HAP exposure in developing countries (Gall et al. 2013).

This thesis aims at designing an air quality feedback system to promote clean cooking. The work described herein focuses on monitoring air quality and providing feedback, as behavior change tools to improve adoption of liquefied petroleum gas (LPG) cookstoves.

The design process of the proposed solution focuses on the intended users' insights, a process known as Human-Centered Design (HCD), and includes a consultation process with potential users to ensure that it fits their needs. HCD process is discussed further in Chapter 4. 


\section{Chapter 2: Literature Review}

In 2001, the World Health Organization (WHO) ranked lower respiratory infections (LRI) - one of the health issues associated with HAP (Bruce, Perez-Padilla, and Albalak 2000) - the number one environmental killer of children under five year of age globally (1.9 million death per year), even ahead of unsafe water and sanitation (1.6 million deaths per year) (Lopez 2006; Ezzati et al. 2006). Likewise, Landrigan et al. (2018) estimate global deaths associated with air pollution from 2005 to 2015 to be higher compared to deaths associated with water pollution in low and middle-income countries, during that period. Research indicates that human exposure to HAP is responsible for around $4 \%$ of the global burden of disease and an extra 2 million deaths in developing countries (Bruce, Perez-Padilla, and Albalak 2000).

In Rwanda, the focus of this work, LRI accounts for over $18 \%$ of deaths in children under the age of 5 (Figure 1). In contract, in the United States, LRI accounts for only $2.3 \%$ of deaths (Institute for Health Metrics and Evaluation (ihme) 2015). 


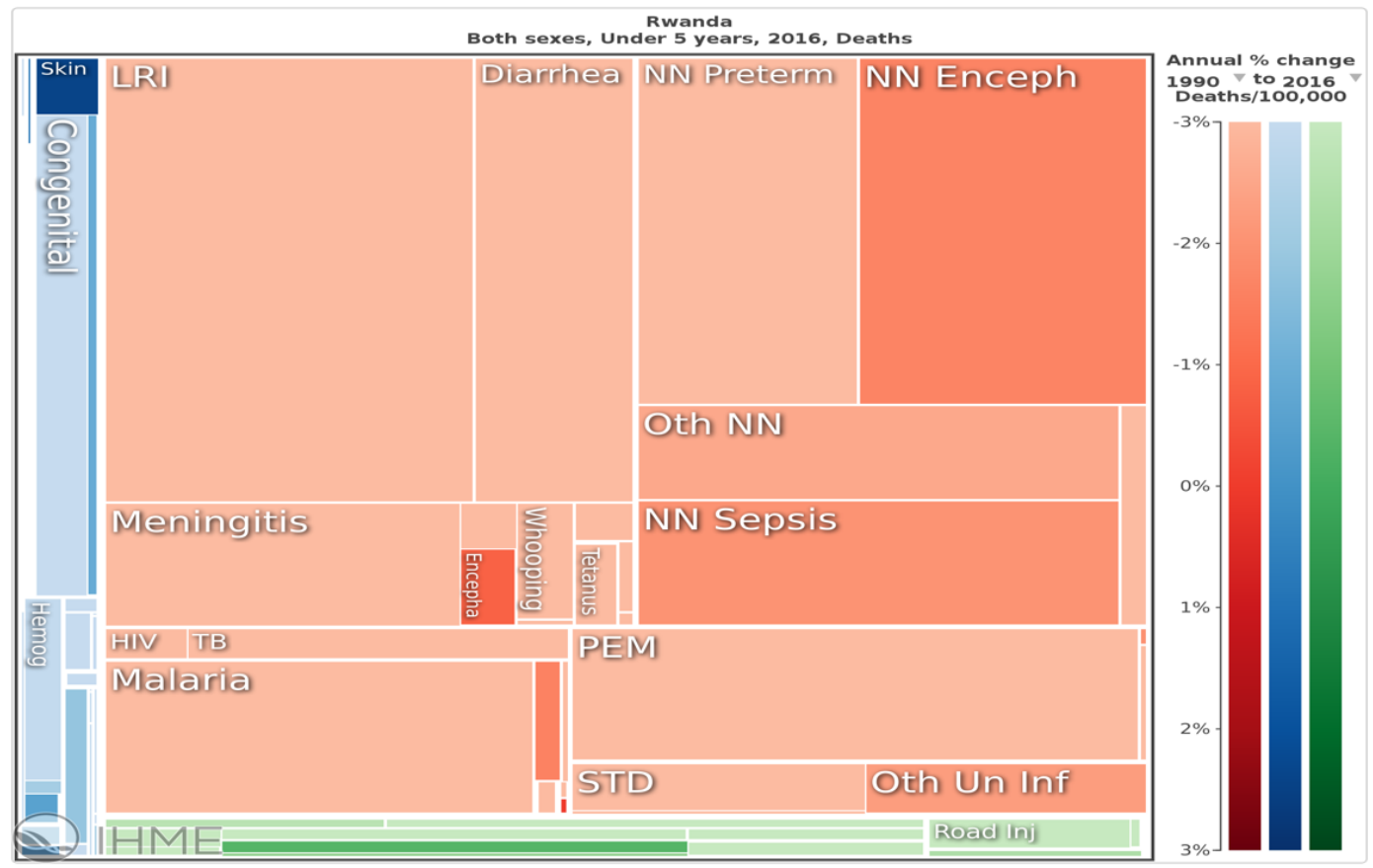

Figure 1: cause of deaths among children under the age of 5 in Rwanda (Institute for Health Metrics and Evaluation (ihme) 2015)

Particulate matter (PM) is one of the main constituents of biomass smoke and poses a serious danger to human health, particularly when small in size (Bruce, PerezPadilla, and Albalak 2000). PM of 2.5 microns in diameter or smaller, commonly referred to as $\mathrm{PM}_{2.5}$, can easily penetrate deep into the respiratory system causing and aggravating several severe health issues (Austin and Mejia 2017; Cohen et al. 2017; Wang, Kindzierski, and Kaul 2015).

According to the Lancet Commission on Pollution and Health, $\mathrm{PM}_{2.5}$ was reported as the fifth ranking mortality risk factor in 2015 , causing around 4.2 million deaths and 103.1 million disability-adjusted life-years in that year alone (Cohen et al. 2017). Among other health issues associated with $\mathrm{PM}_{2.5}$ pollution are lung cancer (Pope et al. 2002; Raaschou-Nielsen et al. 2013), decrease in birth weight (Boy et al. 2002; Stieb et al. 2012), myocardial infarction (Wang, Kindzierski, and Kaul 2015; Thurston et al. 2017) 
and cardiovascular mortality and morbidity (Brook et al. 2010).

Research investigating the source and chemical composition of household $\mathrm{PM}_{2.5}$ in rural and urban Sub-Saharan Africa demonstrates the need for policies that encourage and support the use of cleaner cooking stoves in the region (Zhou et al. 2014). In some rural areas, biomass cooking contributes as high as around $80 \%$ of total indoor $\mathrm{PM}_{2.5}$ and households that depend on burning firewood for domestic energy needs can have average $\mathrm{PM}_{2.5}$ concentration around $500 \mu \mathrm{g} / \mathrm{m} 3$ (Zhou et al. 2014) compared to the WHO and the NAAQS $\mathrm{PM}_{2.5}$ guidelines of $10 \mu \mathrm{g} / \mathrm{m} 3$ and $12 \mu \mathrm{g} / \mathrm{m} 3$ annual means, respectively. Comparable research show that 24-hour averaged $\mathrm{PM}_{2.5}$ concentrations measured during cooking events can reach extremely elevated concentrations, with maximums as high as $10,000 \mu \mathrm{g} / \mathrm{m} 3$ in opposition to WHO guidelines of $25 \mu \mathrm{g} / \mathrm{m} 3$ daily average concentration (Smith et al. 1983; Gall et al. 2013). This is very worrying considering the fact that research associates every $10 \mu \mathrm{g} / \mathrm{m} 3$ increase in $\mathrm{PM}_{2.5}$ concentration with $4 \%$ increase risk of all causes mortality, $6 \%$ increase risk of cardiopulmonary mortality and $8 \%$ of lung cancer mortality (Pope et al. 2002).

Biomass cookstoves are the primary contributor to HAP in developing countries (Gall et al. 2013) and HAP is the cause of an estimated 4 million premature deaths every year (Yadama 2013; Lim et al. 2012). Because of the significant disease burden associated with biomass cookstoves (Rosenthal et al. 2017), various organizations have set up programs that aim at promoting clean cooking technologies.

In 2010 there were more than 160 operating clean cookstove programs worldwide (Gifford 2010). E. Thomas et al. (2015) provide a review of 36 interventions, the majority 
of which focused on stove provisions. Many of the interventions reported stove adoption related challenges, though only $16.7 \%$ of intervention studies provided adoption estimates and $8 \%$ included behavior change interventions in addition to stove provision. The authors of the review advocate for more adoption interventions, emphasize the importance of user's active engagement during intervention design in order to ensure intervention success, and point out the failure of all reviewed interventions to meet WHO air quality regulations.

An example large scale cookstove intervention is described in Barstow et al. (2016), and involved cookstove distribution in over 101,778 households, benefiting over 470,000 people in Rwanda and conducting follow up campaigns in around $97 \%$ of the served households, to promote adoption of the intervention stoves and gather adoption data.

\subsection{A silent killer: need for electronic monitoring of household air pollution}

Sometimes labeled by researchers as a "silent killer", HAP is an issue too big to be ignored. HAP interventions present complex challenges especially insufficient data, preventing proper investigation of the issue (Austin and Mejia 2017). The authors point out the need for more efforts for HAP monitoring and data collection in order to understand the risks that HAP poses and take appropriate actions to remediate or limit damages.

A study investigating public perception and behavior change in relationship to hot weather and air pollution found a promising willingness to change behavior if participants perceived the air quality to be bad, but perceived self-reports of poor air 
quality did not correlate with environmental measurements of $\mathrm{PM}_{2.5}$ and ozone indicators (Semenza et al. 2008), emphasizing the need to leverage electronic air quality monitoring and data access as a behavior change tool. In addition to the general population's limited ability to accurately perceive changes in air quality, studies suggest that air pollution perception may vary with social status. Research attributes this finding to the fact that people in disadvantaged communities have more basic social hazards to battle, like poverty and security related struggles for example, which redirect their attention away from environmental problems (Hohm 1976).

\subsection{Behavior change: promotion, facilitation and monitoring}

Research shows that stove intervention programs cannot achieve their desired impact unless they are highly adopted from the start, and continue to be persistently used over time (Ruiz-Mercado et al. 2011).

Ruiz-Mercado et al. (2011) argue that introduction of a new stove in a household is not just a provision of a new cooking device, but also a modification to the household's existing cooking practices. This makes adoption a complex process that is highly influenced by the way the user interacts with the new stove and new fuels, as well as how they cope with introduced changes in cooking practices.

The users, faced with complexities of cookstove adoption process, allocate the new cookstove and the old cookstove to different cooking practices, depending on what they feel is the best use for each cookstove in relation to their cooking practices, needs and personal preferences. This results in concurrent use of polluting and clean cookstoves: stove-stacking (see Figure 2). The author argues that taking time to 
understand the user's behaviors during that particular phase is key to developing a successful adoption strategy.

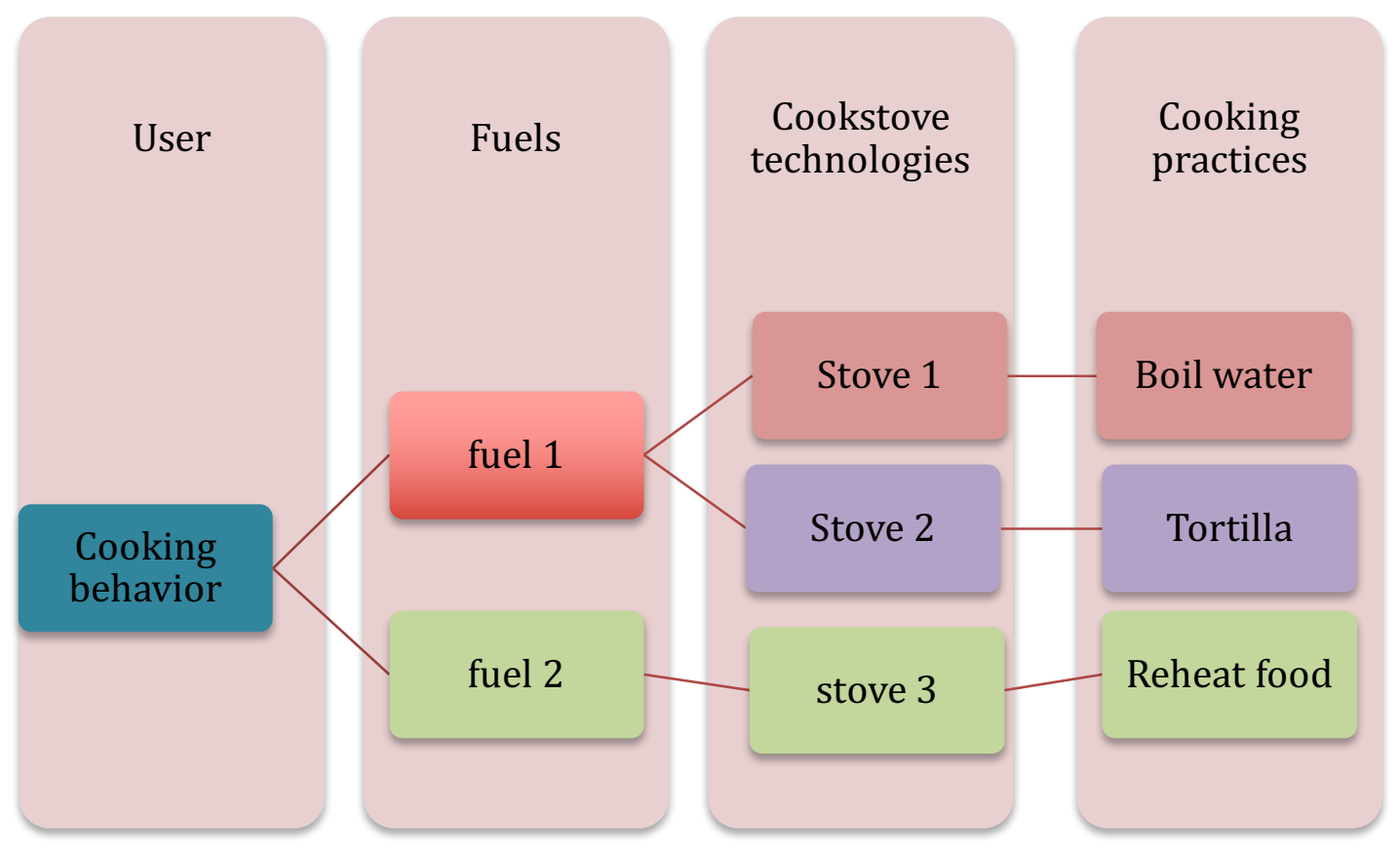

Figure 2: Stove-stacking, adapted from Ruiz-Mercado et al (2011)

Furthermore, complex factors such as gender equity, education, and social and economic status highly influence clean cookstove adoption. There is scientific evidence that women's status is a strong indicator of the kind of fuel that gets used in the household (Austin and Mejia 2017). Communities with overall improved women's social status, that is displayed in access to education and reproductive autonomy for example, empower women to make decisions regarding resources use and result in lower use of solid fuels.

Stove-stacking happens in tandem with fuels stacking, as households transition from traditional fuels to modern fuels, while moving up the "energy ladder". The energy ladder theory - shown in shown in Figure 3 - suggest that people favor more 
sophisticated sources of energy over traditional fuels, as their social economic status rises, and discard traditional fuels (Yadama 2013). However, the theory has been observed to fall short in rural areas and economically disadvantaged communities. Research attributes that failure to people's uncertainty of maintaining the rising income combined with the risk of abandoning a tested energy source in favor of new untested energy source. As a result, households choose to keep the old fuels as well, even when they can afford the new cleaner fuels, combining both with other improved/transitional fuels. Even more worrying, in some cases, some transitional fuels, for example kerosene, are more harmful to human health and the environment that the traditional fuels (Yadama 2013).
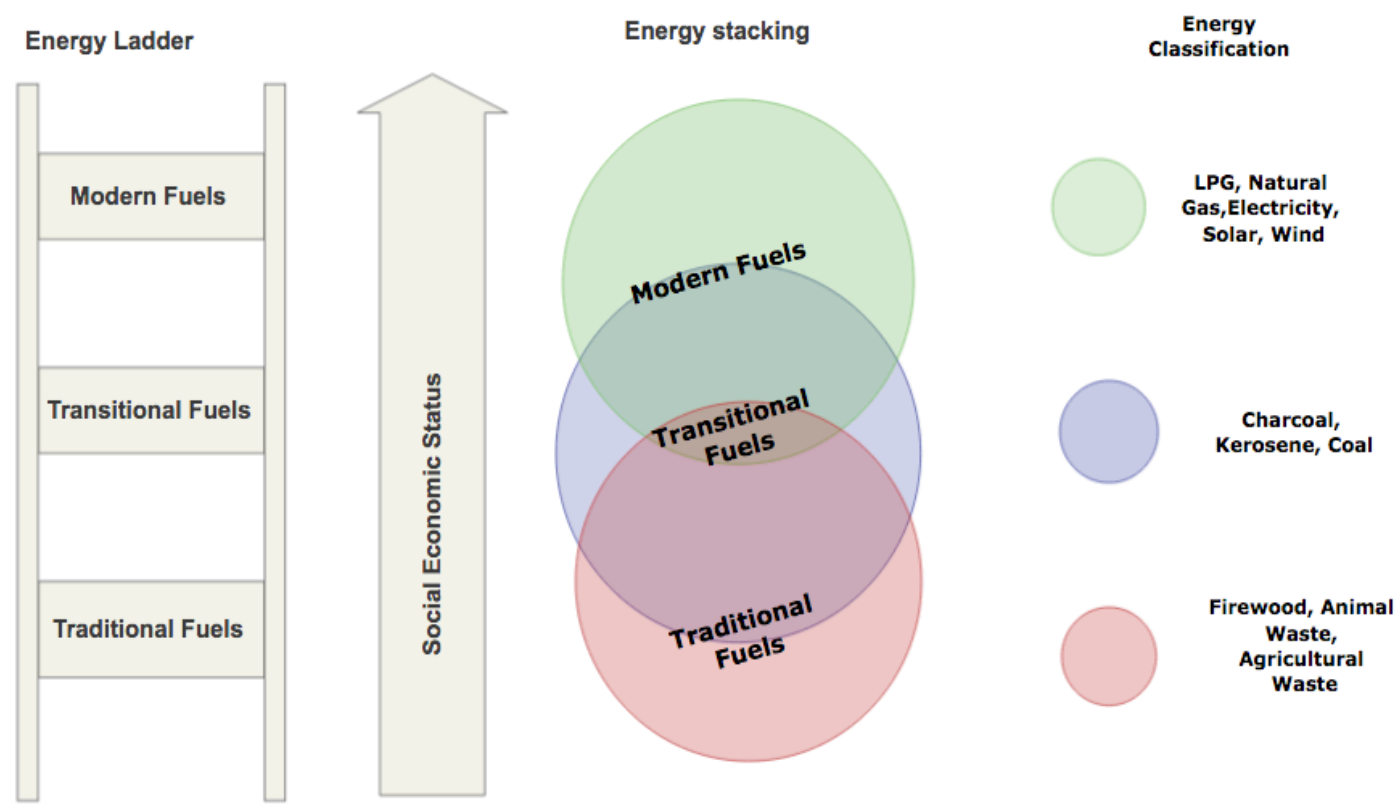

Figure 3: Transition from tradition fuels to modern fuels and staking of fuels. Adapted from Yadama (2013) 
Monitoring of behavior change and stove use has become easier, smarter and free of bias with the emergence of new sensors and continuously evolving information technologies which provide near real-time data and can be scaled relatively easily compared to traditional ways of observation, namely interviews and surveys. In addition, this type of monitoring has been seen to have a positive influence on behavior change (E. A. Thomas et al. 2016). E. A. Thomas et al. (2016) report an initial 63\% increase in use of household water filters, attributed to participants' awareness of the presence of a monitoring device on the filters during the first week of implementation, then dropping to $55 \%$ during the fourth week of the study. This finding suggest that monitoring technologies are able to influence behavior, and as such, could be leveraged as a behavior change tool. Often referred to as the "Hawthorne effect", the effects of changes in behavior resulting from the study subject's reaction to the fact of being under study (Wickström and Bendix 2000) is another factor that has been shown to influence behavior change.

\subsection{Feedback as a behavior change tool}

A literature review on the role that smartphones play in encouraging physical activity in adults reported feedback to be an important factor. The review's findings show that personalized feedback and adaptation of interventions to the individual's specific

conditions and context yield better behavior change outcomes (Stuckey, Carter, and Knight 2017).

Another study investigating personalized feedback for physical activity behavior change showed a significant physical activity increase and more willingness to follow the 
physical activity app suggestions in the group receiving personalized feedback compared to a group receiving generic feedback. In addition, participants reported personalized suggestions to be easy to act on and generic suggestions difficult to act on (Rabbi et al. 2015).

Likewise, the impact of feedback on behavior change has been observed in several other disciplines. Increased adherence to antiretroviral treatment was achieved by a combination of short message service (SMS) reminders and real-time patient behavior monitoring (Haberer et al. 2016). Improvement of patients' glycemic conditions was shown when provided with a continuous graphical representation of glucose levels in their blood (Rodbard et al. 2009). Increased physical activity was shown using a trackingtexting system, as opposed to no increase when the texting element was excluded and a decrease in physical activity for participants who did not know they were being monitored (Martin et al. 2015).

In a similar study, successful driving speed reduction behavior change was achieved through audio advisory combined with visual display of driver's incentive in the form of earned rewards (Reagan et al. 2013).

Klepeis et al. (2013) is an example of behavior change intervention study that is very similar to the focus of this thesis. This study observed second hand smoke exposure reduction in favor of children and other non-smokers in the household, as a result of smokers' response to real-time audio-visual feedback of indoor air pollutants levels. Participants who had initially openly indicated that they would not change their smoking behaviors maintained high levels of second hand smoke in the shared living areas with 
small decreases in bedrooms. The authors argue that graphical display in particular, may present more persuasive evidence for families to adopt healthier behaviors. The authors also argue in favor of a more customized and more diverse choice of colors, sounds, icons and other feedback features to improve effectiveness and user-friendliness.

Based on the literature discussed above, combining stove use monitoring with reminders to the user of the benefits of healthy cooking, and providing users with contextualized feedback and access to data, may be an effective way to address the stovestacking challenges faced by clean cooking interventions. 


\section{Chapter 3: Study Context}

\subsection{The Household Air Pollution Intervention Network (HAPIN) Study}

An example of a current indoor air pollution efficacy trial is the Household Air Pollution Intervention Network (HAPIN) Trial, an international study designed to assess impacts of LPG cookstove and fuel provision intervention on health. The trial is funded by the National Institutes of Health (NIH) and the Bill and Melinda Gates Foundation and led by Emory University, while the Global Alliance for Clean Cookstoves and the Global LPG Partnership provide expert counsel (Emory University Rollins School of Public Health 2018).

The HAPIN study involves more than 7,200 participants from Guatemala, India, Peru and Rwanda and is expected to last a minimum of 4 years. In each country, 800 pregnant women, their infants and 200 older women will be recruited. The study participants will be provided with an LPG cookstove and LPG fuel free of charge for 30 months during the study. For 18 months, they will receive thorough behavior change messaging combined with personal exposure and stove use monitoring. In addition, the health of both the mother and their child will be extensively (Emory University Rollins School of Public Health 2018).

HAPIN seeks to answer two main questions: first, how clean does a cookstove technology have to be to yield measurable health outcomes? And second, what can be done to ensure high and sustained clean cooking adoption? HAPIN is attempting to provide answers to these questions in an effort to tackle the disease burden associated with HAP (National Institutes of Health 2018). 
One of the HAPIN Trial target countries, Rwanda, is reported to have around $85 \%$ of its energy use tied to biomass fuels, a factor that not only raises concerns of human exposure to air pollution, but also highly contributes to environmental degradation and deforestation (Marge 2009). The HAPIN study could positively affect decision making and inform future HAP and energy interventions in Rwanda, the other three trial countries, and several other countries that are experiencing similar air quality and energy challenges.

Research report stove-stacking as the major barrier to achieving health benefits expected from clean cooking (Johnson and Chiang 2015), stressing the importance of ensuring that clean stoves are not used simultaneously with polluting stoves. The HAPIN trial, being an efficacy study and having taken measures to address the stove stacking issue through behavior change interventions and fuel provision, is expected to provide insight into the maximum health benefits that can be achieved through clean cooking.

The air quality feedback system described in this thesis, will be implemented in a sub-study within the HAPIN Trial, with aim of assessing the impacts of feedback on LPG cookstove adoption and investigating how indoor $\mathrm{PM}_{2.5}$ levels correlate to health outcomes among other objectives. 


\section{Chapter 4: Human-Centered Design Overview}

Human-Centered design (HCD) aims to be a "constructive, optimistic and experiential design process that allows creation of innovative solutions by deeply investigating consumers' insights and leveraging rapid prototyping" (Brown and Wyatt 2010). HCD is based on building empathy with users, a culture of prototyping as well as tolerance of failure. According to Kolko (2015), HCD may be the best tool available to make users' interactions with technologies feel natural, effortless and enjoyable.

Studies suggest that HCD can boost user's engagement, which gives the new solution an advantage and boosts its odds of success and sustainability (Vechakul, Shrimali, and Sandhu 2015). In addition, its flexible nature and disposition to embracing ambiguity give designers a larger poll of possible solutions to choose from, allowing them to adapt it even more to the users' context.

In the public health sector, Matheson et al. (2015) suggest that HCD is the ideal tool to use against the "knowing-doing gap," which the authors say is "the lack of action despite knowing better behaviors' benefits, to avoid destabilizing the existing environment" in disease prevention interventions. This research suggests that HCD can be combined with evidence based data to foster success of disease prevention efforts.

Research shows that several organizations including Non-Governmental Organizations, public health agencies and health systems are embracing the use of HCD to promote or enhance public health interventions, but documentation of methods, processes and results is limited, making it difficult to reproduce those tools for further use (Bazzano et al. 2017). 


\section{Chapter 5: Methods}

\subsection{Study Objectives}

This thesis aims at designing an air quality feedback system, to promote healthy cooking. It leverages HCD process, sensor instrumentation and the provision of real-time feedback, towards the development of solution, that would discourage stove-stacking and improve LPG cookstove adoption and exclusive use.

In September 2017, we applied HCD methodologies to a consultation process with potential LPG cookstove users in Kayonza District, Eastern Province of Rwanda, to seek their insights and inform design of the air quality feedback system. The HCD methodologies described in this thesis focus on investigating and understanding users' personal, cultural and community setting concepts that influence their cooking culture and attitude towards clean cooking. The procedures applied seek to identify what behavior change triggers draw users towards clean cooking, what type of feedback and how much feedback is appropriate in order to inform the design of the air quality feedback system.

Because this research involves human subjects, it was necessary to determine whether an institutional review would be required. The HCD consultation process was determined by the Portland State University Institutional Review Board not to require further review (Research Integrity "Review Not Required” Determination for submission \#174324, entitled: "Dynamic Sensors on Cookstoves to Encourage and Reinforce Healthy Behavior Change - Exploratory Interviews"). 
This document provides detailed information on the HCD processes used and the results, to inform and facilitate future use and/or replication of the developed air quality feedback system.

\subsection{Participants selection process}

The HCD process targeted a representative group of mothers between the age of 18-35 years old from Kayonza District, Rwanda who were the primary cook for their families. A local community health worker helped select participants, ensuring representation of different education levels and social and economic status in order to have a more community representative sample.

The resulting representative sample consisted of 10 mothers aged between 26-38 years old with children between the age of 3 months and 13 years. $70 \%$ of participants had children under five years of age. Participants' education levels ranged from needing help reading to school teachers. There were both married and single mothers as well as a diverse economic representation. $20 \%$ of participants had LPG cookstoves and afforded fuel with relative ease.

\subsection{HCD Methodology}

The HCD process methodology included:

- Household interviews

- Card sorting

- Peer discussion meeting

- Voting 


\section{Household interviews}

The HCD team conducted 10 individual household interviews. We met with each of the 10 recruited participants in their home, to identify clean cooking behavior change triggers, air quality feedback content and air quality feedback delivery options. The interviews included questions about existing feedback technologies in the community, meanings of colors and icons, which household members are more interested in the air quality feedback information, the household cooking practices and culture and preferred alarm system (See Appendix C for a complete list of survey questions).

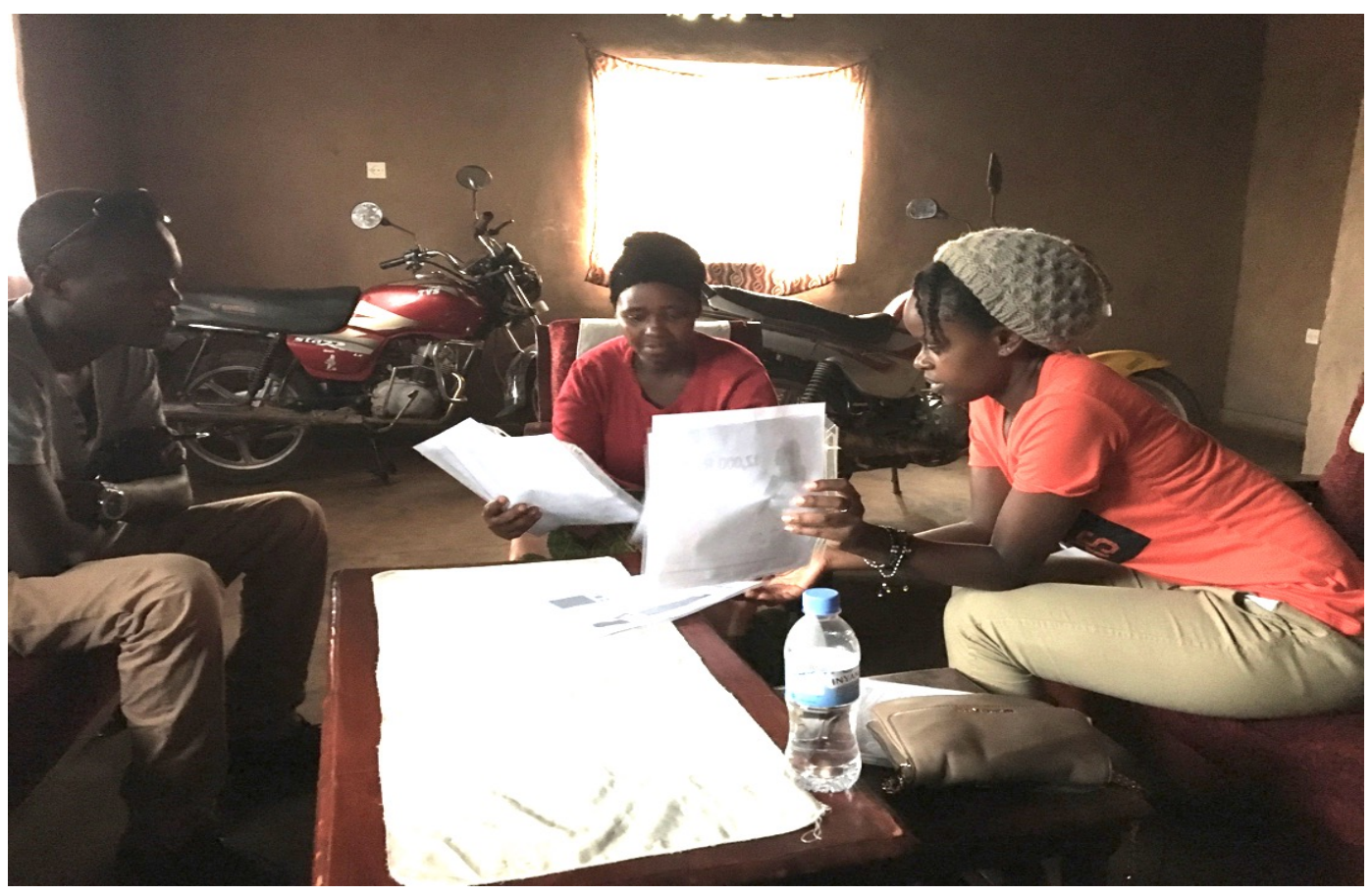

Figure 4: HCD process work in Rwanda

Figure 4 shows the HCD consultation process in progress in Rwanda. Interviews were conducted in Kinyarwanda, and the team took time to write down the information and make sure that everything was properly captured before moving on to the next household. Recording each household collected data right after conducting the interviews 
was a very important part of the field work, to ensure that individual responses are captured as authentically as possible, free of biases and mistakes that might come from losing touch with particularity/individual realities/ of that particular household as we progressed in our work, talking to other households. Translation of data from Kinyarwanda to English was done by two Kinyarwanda native speakers with bachelor's degrees (including the author of this thesis) and one English native speaker (with a master's degree) to ensure nothing was lost in translation.

\section{Card sorting}

Ten cards were designed for HCD card sorting activities using SketchUp software and printed on A4 paper, with plastic sleeves to prevent ink from wearing off. Each had an image, a verbal description in Kinyarwanda, and a small identification tag for quick result recording. At the beginning of each interview, the cards were arranged randomly to prevent bias. These cards were then given to participants for them to arrange, from what was most significant as a behavior change trigger to the least significant and the most preferred message delivery technique to the least preferred. Participants were asked to provide verbal rationale for their choices and to name other things they would like to be included on the cards in order to better understand their motives and ensure that the design solution is best adapted to them.

Figure 5 presents an example of the behavior change triggers' cards (See appendix A for a complete set) 

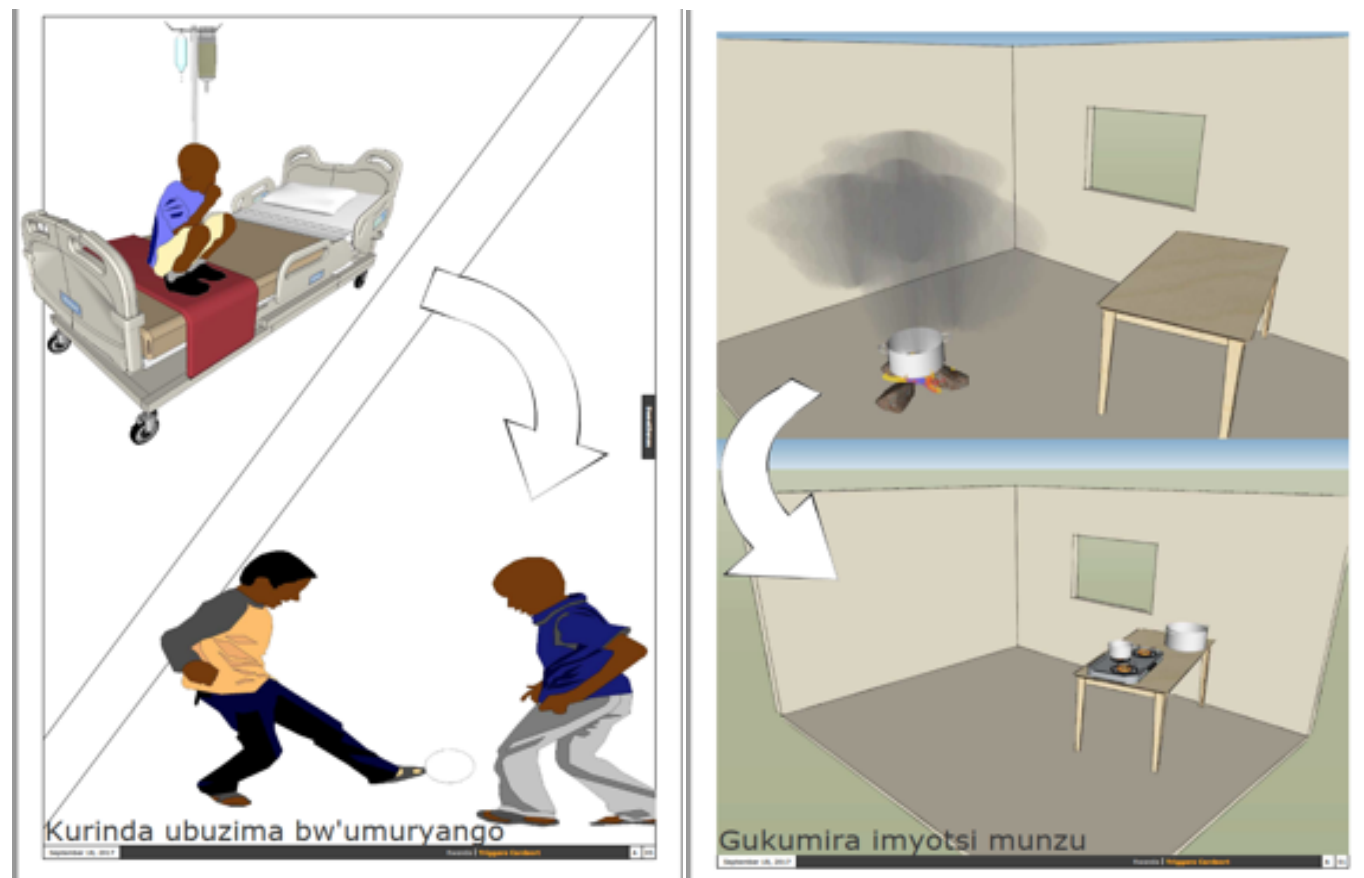

Figure 5: Example cards, depicting children's health and smoke, as one potential behavior change trigger that may influence LPG cookstove high adoption and exclusive use

\section{Peer discussion meeting}

Nine of the study participants who had participated in the household interviews were brought together to be engaged in a group discussion. All ten women were invited, but one participant was not able to attend the group meeting for reasons of which she informed the HCD team in advance and expressed regret of not being able to attend. The participants discussed their individual preferences and received feedback on their opinions and choices from their peers. They were invited to comment on their peers' opinions as well.

The peer discussion meeting was also used as an opportunity for the HCD team to test cards representing new ideas that were obtained during household interviews. 


\section{Voting}

With the intention of capturing the selected sample preferences as a group, the voting activity was used to break ties among competing ideas from household individual interviews and identify what the group's opinion was. For example, if one household said that deforestation is the most important clean cooking behavior change trigger, and another said that smoke nuisance is the most important clean cooking behavior change trigger, these results were put into a vote, to see what the majority of the study population think is the most important clean cooking behavior change trigger. 


\section{Chapter 6: Results}

\subsection{Cookstove technologies in the community}

During household interviews, four types of cookstove technologies (see Table 1) in use in the community were identified:

\section{Rondereza}

"Rondereza", Kinyarwanda word for "being thrifty", is a locally made biomass reduction cookstove. Usually built-in to the cooking place and static, Rondereza cookstoves are part of the many Rwandan government initiatives first initiated in the late eighties to tackle deforestation.

\section{Three stone fire cookstove}

Three stone fire cookstoves are a traditional cookstove technology, common in developing communities. They consist of three stones that support the cooking pots while biomass is burnt between them under the pot. These cookstoves produce a large amount of smoke and particulate matter as a result of incomplete combustion. They can also be moved around easily when the user wants to change their cooking place for environmental or personal preference reasons.

\section{Charcoal cookstove}

Charcoal cookstoves consist of a clay or metallic apparatus that charcoal is put on and burnt, and the cooking pot put on top of charcoal. This type of cookstove usually 
produces less smoke than both the Rondereza and Three stone fire cookstove, but it produces more carbon monoxide as shown by Eq. 1 and Eq. 2, and charcoal is more expensive than raw biomass. See charcoal burn off reactions below from Várhegyi et al. (2012).

$$
\text { Biomass }+\mathrm{O} 2 \rightarrow \text { Charcoal }+ \text { volatiles } \quad(E q .1)
$$

Charcoal $+\mathrm{O} 2 \rightarrow$ Ash $+\mathrm{CO} 2, \mathrm{CO}, \mathrm{H} 2 \mathrm{O}$ and minor volatile products $\quad$ (Eq. 2)

(Várhegyi et al. 2012)

\section{LPG cookstove}

2 LPG cookstoves were identified in the sample study community. 
Table 1: Summary of cookstove technologies reported in the community (The Charcoal stove picture was taken by Liliose Uwineza and the other cookstoves pictures are from Delagua Health and the HAPIN Trial. They were used with permission.)

\begin{tabular}{|c|c|c|c|}
\hline $\begin{array}{l}\text { Stove } \\
\text { type }\end{array}$ & Image & Fuel & $\begin{array}{c}\text { Relative Cleanliness and } \\
\text { efficiency }\end{array}$ \\
\hline $\begin{array}{l}\text { Three- } \\
\text { stone } \\
\text { Fire } \\
\text { stove }\end{array}$ & & $\begin{array}{l}\text { Raw } \\
\text { biomass }\end{array}$ & $\begin{array}{c}\text { Poor cleanliness and energy } \\
\text { inefficient }\end{array}$ \\
\hline $\begin{array}{l}\text { Ronder } \\
\text { eza } \\
\text { "Be- } \\
\text { Thrifty" }\end{array}$ & & $\begin{array}{l}\text { Raw } \\
\text { biomass }\end{array}$ & $\begin{array}{l}\text { Poor cleanliness, more efficient } \\
\text { than the former }\end{array}$ \\
\hline $\begin{array}{l}\text { Charco } \\
\text { al stove }\end{array}$ & & Charcoal & $\begin{array}{l}\text { Produces less smoke, but more } \\
\text { carbon monoxide }\end{array}$ \\
\hline $\begin{array}{l}\text { LPG } \\
\text { stove }\end{array}$ & & LPG & $\begin{array}{l}\text { Relatively clean and efficient } \\
\text { technology }\end{array}$ \\
\hline
\end{tabular}

\subsection{Study sample cooking habits}

Rondereza was the most used cookstove technology with $70 \%$ usage rate, followed by three-stone, charcoal and LPG cookstoves with usage rates of $60 \%, 30 \%$ and $20 \%$ respectively (see Figure 6). 


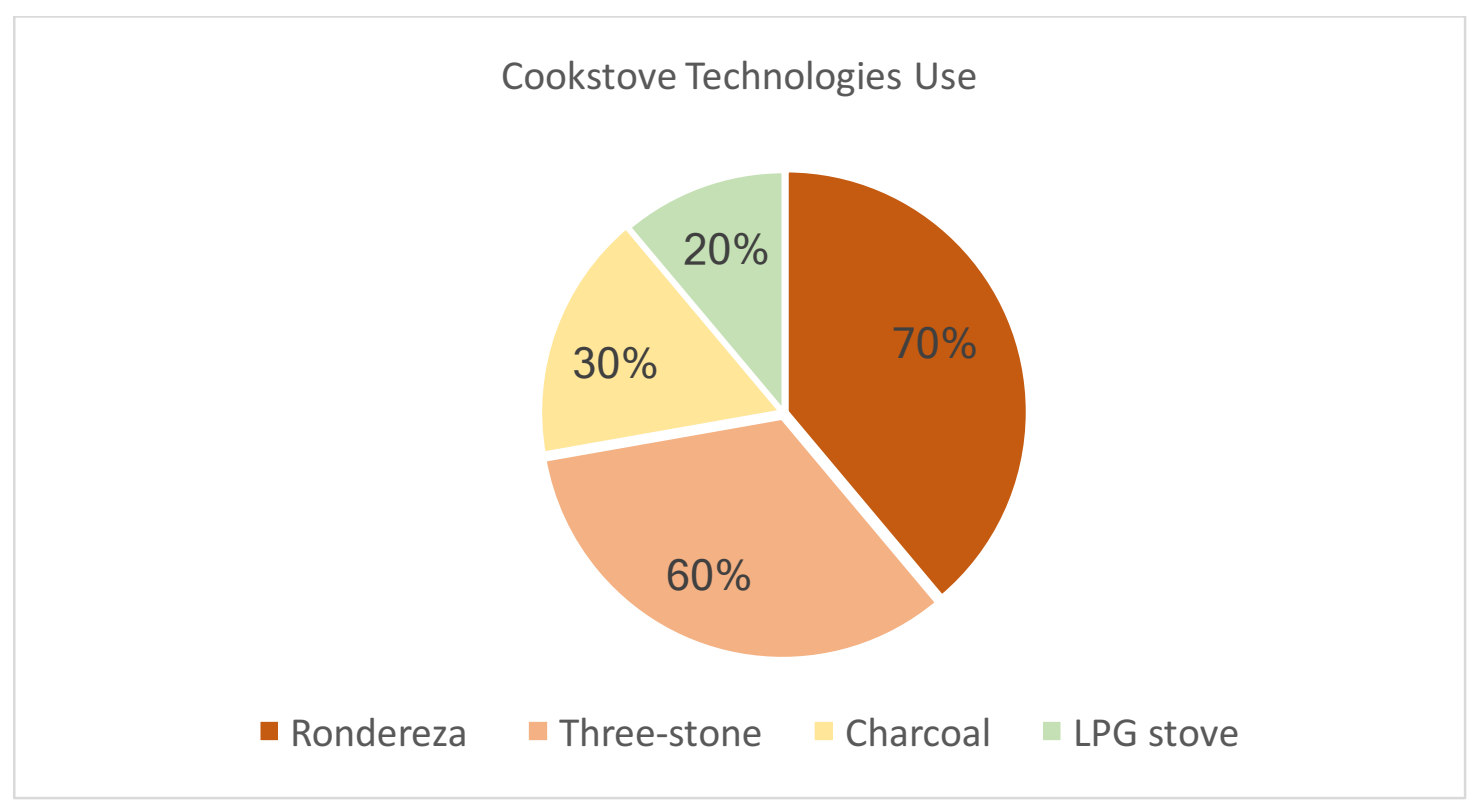

Figure 6: Stove technologies use reported by study participants

\subsection{Stove-stacking}

Stove-stacking was observed in the community (see Figure 7 ). 50\% of participants said they use two or three stove types concurrently, while 30\% said they use three-stone fire stove exclusively and $20 \%$ use Rondereza exclusively

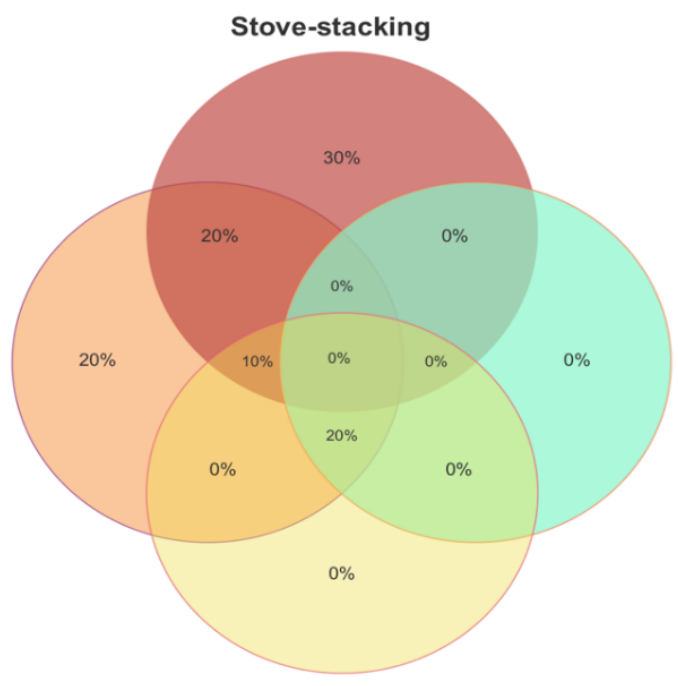

Stove types

Figure 7: Stove-stacking patterns reported by participants 
Rondereza was the most used cookstove (at $70 \%$ ) followed by three stone fire, charcoal and LPG cookstove at $60 \%, 30 \%$ and $20 \%$, respectively (see figure 6). Rondereza and three stone fire cookstoves were close in usage and were the only cookstoves technologies observed to be sometimes used exclusively.

It was observed that the cleaner and/or expensive the stove gets, the odds of it being used exclusively are reduced. The LPG cookstoves were always combined with two more other cookstoves types and so were charcoal cookstoves.

\section{4. $L P G$ cookstove exclusive use and perception}

Study participants had positive perception regarding LPG cookstove. They associated LPG use with cleanliness, time saving and environmental sustainability. They said that cleanliness and ease of use, make LPG cookstoves appealing to their husbands, enough for them to help with cooking. They see them as a modern future way of cooking, as other fuels - charcoal for example - are becoming expensive. However, there were concerns expressed by participants including the high cost of equipment and gas purchase, risk of gas explosion, risk of inhaling gas and difficulties of repairing or replacing equipment.

$100 \%$ of participants argued that it is financially illogical to consider exclusive use of LPG cookstove, as some of their regular dishes require cooking for a long time, which would exhaust the expensive fuel. These types of dishes are left alone cooking. While participants did not explicitly say it, concerns of leaving the LPG cookstove on and unattended for, could be a factor that would negatively affects adoption. However, despite that, they all indicated that they would try to use a LPG cookstove exclusively, if 
continuous free fuel supply was provided. They strongly argued that no additional incentive would be required.

The HCD results indicate that LPG cookstove introduction into the household cooking culture results in changes of the cooking location. $90 \%$ participants said they would install the LPG cookstoves inside the main house, while $10 \%$ would expand on their main house to make a room for the new stove.

\subsection{Colors and iconography}

Part of the HCD product design process includes examining visual design features that make sense within the user's cultural context, rather than relying on the designer's own biases. In order to inform the graphic design of the air quality feedback system, personal color perceptions and iconography relevance were tested. The HCD team asked participants what colors and icons have specific meanings to them, and what meanings those might be. Then the HCD team asked about other common colors and icons that were not volunteered.

Red, yellow and purple were the most popular colors volunteered. Most colors were both positively and negatively perceived except for green and white that were positively perceived and purple and grey that were negatively perceived (see Table 2).

Likewise, both volunteered and tested icons had various interpretations. For example, a "thumbs-up" sign was interpreted as good, a salutation, a sign of approval while "thumbs-down" sign was interpreted as meaning that something did not work out as expected or it will not work. Most participants volunteered a circular movement of the index finger as a "turning around" sign. 
Table 2: Color perception reported by participants

\begin{tabular}{|c|l|}
\hline Color & Perception \\
\hline Green & Positive \\
\hline Grey & Negative \\
\hline Yellow & Positive/Negative \\
\hline Red & Positive/ Negative \\
\hline Purple & Negative \\
\hline White & Positive \\
\hline Brown & Positive/Negative \\
\hline
\end{tabular}

\subsection{Identified clean cooking behavior change triggers}

During card sorting activities, participants were asked to rank several clean cooking benefits from the most important to the least important. The benefits represented on the cards were: absence of smoke, avoiding black walls, protecting trees, protecting infants' health, protecting kids' health, money and conducive for hosting friends. Card meanings were discussed before sorting, and individual choices were discussed after sorting to ensure context uniformity between the HCD team and participants.

The protection of trees was identified as the most prominent factor that would influence participants adoption of clean cooking, followed by children's health protection. Nuisance and aesthetic factors such as the presence of smoke and blackening of house walls came last (see

Figure 8). 
Participants explained their tendency to put the protection of trees before children's protection, saying that deforestation affects rain regularity and soil erosion, which then affect agricultural activities that they depend on to feed their families. They explained that the first step of protecting their children is to make sure they do not starve.

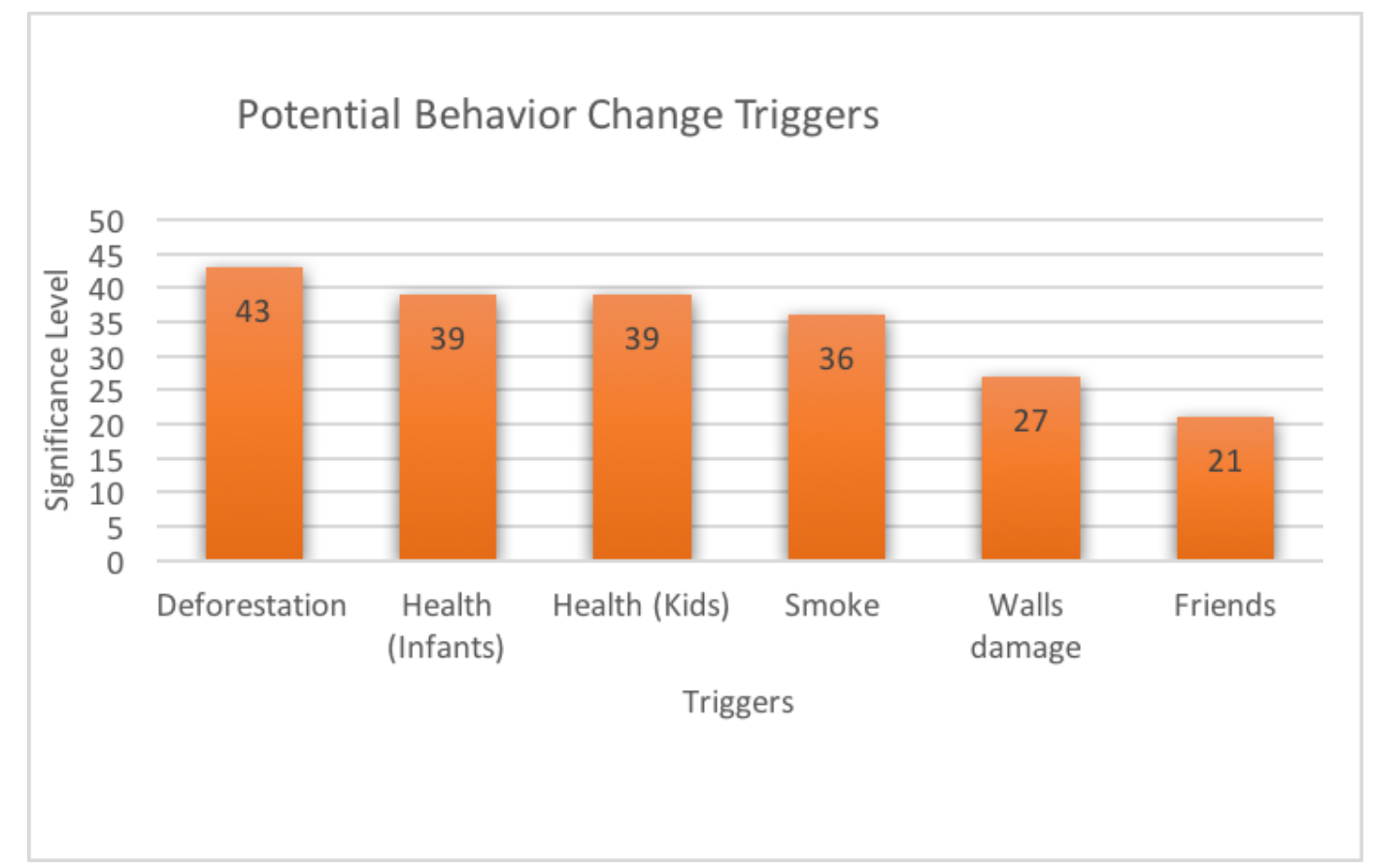

Figure 8: Behavior change triggers in order of significance

\subsection{Air quality feedback delivery means}

Card sorting activities were used to identify the appropriate means of delivering air quality feedback to participants. The tested feedback systems were: Audio, Poster, SMS and colored lights. See appendix B for a complete set of feedback delivery means cards. Participants were asked to arrange different feedback systems from most preferred to the least preferred. Their choices were then discussed and recorded. 
The most preferred system for receiving air quality feedback was direct audio feedback, followed by a visual poster and colored lights, while the least preferred technique was SMS (see Figure 9).

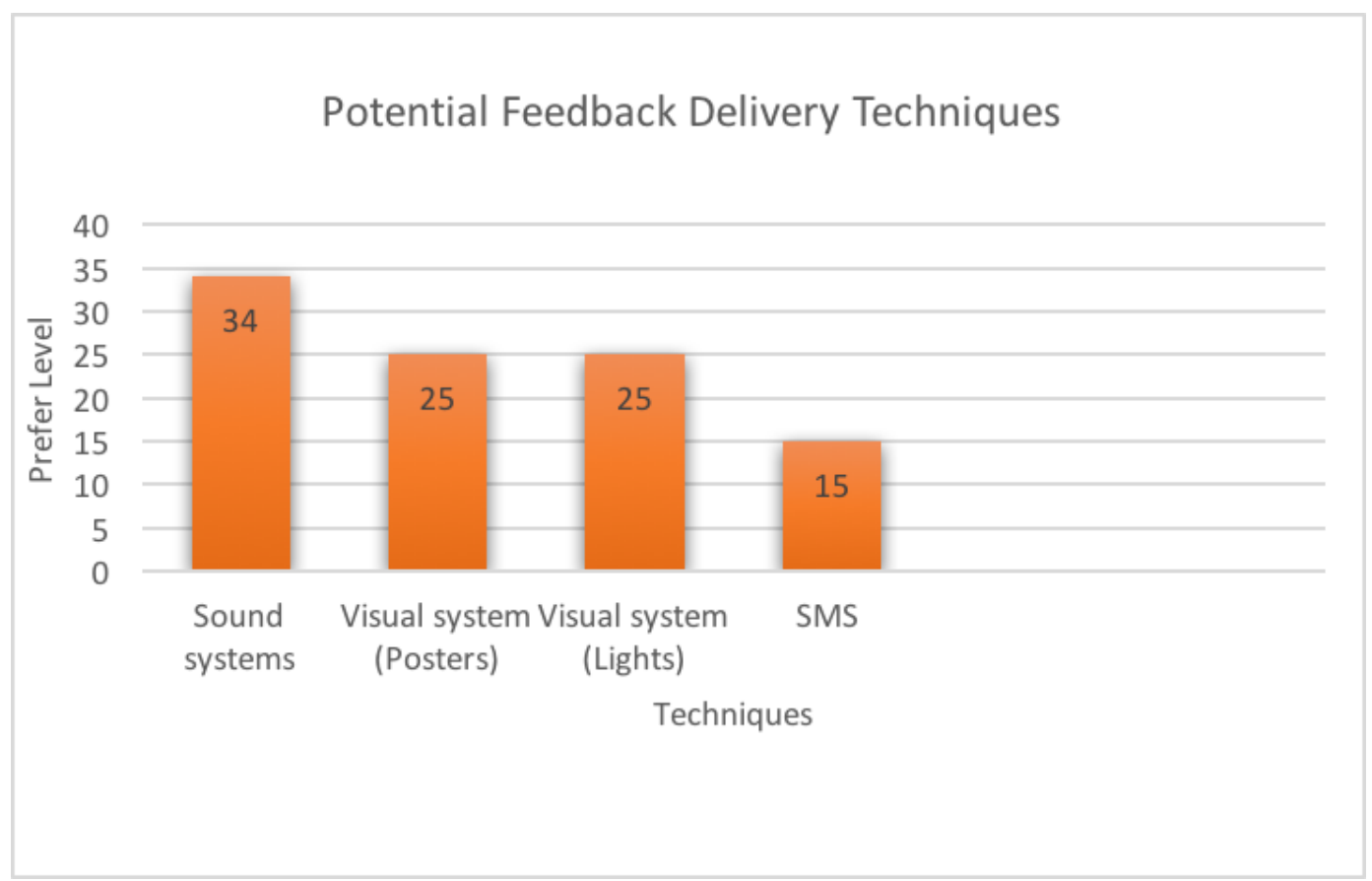

Figure 9: Feedback delivery means in order of participants' preference

Participants explained their first choice of audio to be a system that would notify them when the air quality is bad. They would want the sound to signal air pollution levels above a certain threshold, inciting them to take action, and stop when something has been done to bring pollution levels back down.

They explained their disinclination towards SMS cellular text messages, saying that it is easy to ignore and does not carry any sense of urgency. 


\subsection{Peer discussion and group consensus through voting}

Nine of the ten participants were invited to a peer discussion meeting so that they could discuss individual choices with their peers as well as give and receive feedback on their opinions and personal preferences. The HCD team used this opportunity to break ties among competing preferences, test combination of ideas and seek further insight into specific design questions. Ties were broken among infant and kids' health triggers, which had the same level of importance based on individual interviews, and colored lights and visual poster feedback systems, which had the same level of preference. As a result, infants' health trigger was voted more important that the kids' health trigger and the poster system was voted more preferred than a colored light system.

New cards depicting combined audio and visual feedback systems were made based on initial results from household interviews, after participants had chosen an audio alarm to communicate poor air quality. A second set of cards was made to examine user interaction with the air quality feedback system. For example, one set of cards examined whether users should be able to turn off the alarm without actually reducing air pollution. Participants strongly argued against this, saying that some family members would opt to just switch the alarm off instead of taking action to bring air pollution levels down.

Several sound options were discussed including a "bike-horn" like sound, ambulance alarms, children's voices, music, and natural sounds like rain or a forest fire. Participants were in favor of a musical sound. They also suggested that the sound volume goes from high to a relatively lower volume that can be heard in the household until air pollution levels have dropped. 
One of the cards developed to be tested during the peer discussion meeting, inspired by household results, illustrated the use of a sound system in combination with a visual poster. Participants' general opinion turned in favor of the combined audio-visual option over sound only and poster only options.

While discussing the visual feedback option, participants favored the visual depicting children's health in place of a trees-based visual. They said that a visual representation related to trees inside their homes would not make much sense, and as a consequence, would be less likely to drive behavior change. 


\section{Chapter 7: Discussion}

The HCD results indicate a preference for a combined visual feedback and audio alarms and a strong consensus around deforestation and health as triggers that may influence users' behavior towards promoting exclusive use of LPG cookstoves.

The common view of HCD participants favored a health-based visual air quality feedback over an environmental visual air quality feedback.

It is worth noting that since the air quality feedback is about the household air quality, not the area ambient air quality, a visual representation based on human health draws a much more direct association, than a visual representation based on deforestation. The impact of air pollution from household biomass cooking on trees is perceived as long-term, and therefore conveys less urgency for immediate action and provides a less convincing visual proof of real-time action drawbacks and benefits. Hence, health was chosen to be the leading theme/behavior change trigger during the air quality feedback system design.

There were both "positive" and "negative" perceptions associated with the tested colors, except for green/white and grey/purple which had all positive and all negative perceptions, respectively. As a result, green was chosen for positive representations and grey for negative representations, during the air quality feedback system prototyping. 


\section{Chapter 8: Development of the audio-visual feedback display}

Informed by the HCD results, we developed an audio-visual feedback display that uses sound, graphics and a behavior change message theme that fit in the study participants' context and community setting.

\subsection{Visual feedback prototyping and testing}

From the HCD results it was clear that the feedback theme of focus was going to be health based. An initial lungs mockup was made, with grey dots filling the lungs to symbolize air pollutants accumulation in the human respiratory system. The grey color was inspired by the fact that participants perceived that color as conveying a negative message. As $\mathrm{PM}_{2.5}$ levels increase in the household, more grey dots are visualized in the lungs.

The design team decided to include as many HCD-obtained insights as possible by incorporating other discovered important behavior change triggers in the feedback. The lungs were enclosed in a human body outline which was later changed to an infant's body outline instead, to reflect the expressed importance of infant health.

The initial background consisted of Rwandan flag colors: green, blue and yellow,

which were later replaced by a landscape view showing green trees in the far view and green banana trees in the near view, to symbolize favorable agriculture environment and prosperity respectively, again, to incorporate the expressed importance of deforestation as a clean cooking behavior change trigger.

Figure 10 shows the air quality feedback system at different prototyping stages. 


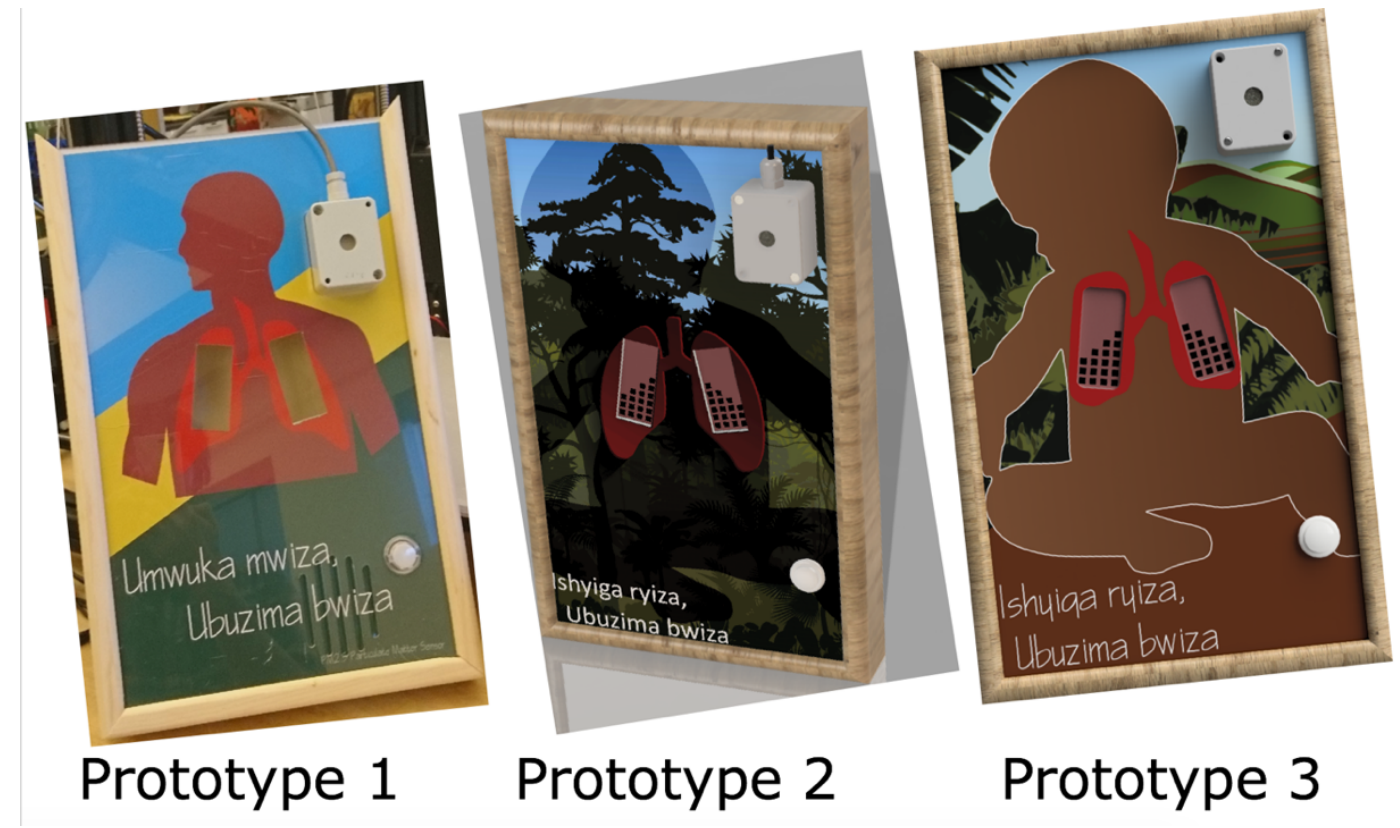

Figure 10: Air quality feedback system prototypes

\subsection{Audio feedback prototyping and testing}

The initial audio system prototyped was a popular Rwandan song, but due to challenges related to securing rights to use the song, the team opted for using Rwandan drum beats instead. The beats will be made and recorded in Portland, Oregon, USA.

\subsection{Final Product}

The final air quality feedback system incorporates themes, colors and clean cooking behavior change triggers identified during the HCD process. The resulting product is a health-centered graphical display indicating the current air quality, combined with an audio alarm that goes off when there is an upswing in air pollution, resulting from the presence of a biomass stove cooking event (see Figure 11).

The health-centered graphical display depicts lungs on an infant's body, indicating the current concentration of $\mathrm{PM}_{2.5}$, in the form of dark grey colored dots which 
fill the lungs as PM2.5 levels rise. An eInk display was chosen for graphical representation of current air quality because of its low power requirement. The display is powered by alkaline D-cell batteries, replaceable and relatively long-lasting. The display's background shows a typical Rwandan agricultural landscape, with banana trees, terraces and a variety of other green vegetation. The background symbolizes prosperity that comes from the presence of a conducive environment for agriculture.

The alarm threshold is household specific and depends on the measured household baseline particulate matter concentration and the experimentally measured concentration when there is biomass cookstove operation going on in the household. The personalized alarm threshold takes into account other sources of particulate matter in the house's environment that are not related to biomass burning cookstoves. The alarm plays an agreeable familiar sound/song, and stays on, until particulate matter concentration has dropped below the set personalized threshold. HCD participants did not want a manual option of turning off the alarm, saying that kids and other family members would be tempted to just go for that option instead of stopping biomass burning that caused the change in the household's air quality.

The audio-visual feedback display also includes a reminder message printed on the health poster, with the intention of constantly reminding the user why it is important to use the LPG stove exclusively as well as an air quality monitor/sensor that measures real-time PM2.5 concentrations, temperature and relative humidity. All units are enclosed in a wood frame and will be hung inside a house while in use. Dr. Daniel Wilson and Taylor Sharpe contributed to the design process of this product. 


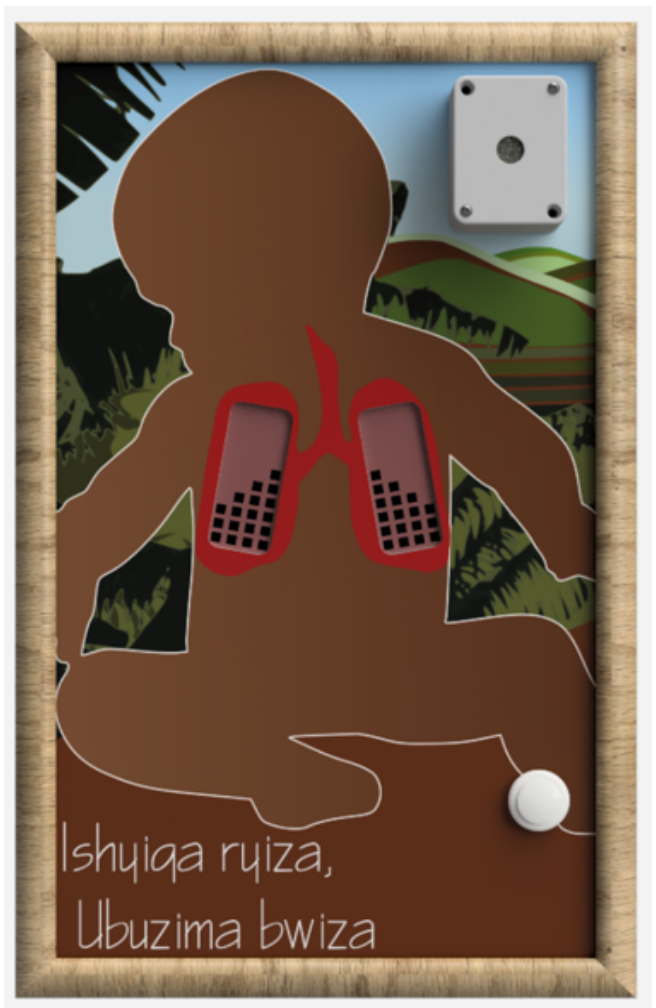

Figure 11: The final product (audio-visual air quality feedback system)

\subsection{Air quality sensor and data logging process}

The chosen air quality sensor is the MiniPATS from the Berkeley Air Monitoring Group, designed to measure high and low sensitivity particulate matter levels that are typical of biomass burning for cooking and heating purposes in less developed rural areas. The sensor design was inspired by the idea of adapting commercial smoke detectors to monitoring of PM and as such relied on diffusion and natural air flow to bring aerosols into the sensing chamber. The sensor also measures relative humidity and temperature (Pillarisetti et al. 2017).

\subsection{Cost estimates}

Figure 12 shows estimates for one unit air quality feedback system product. One 
assembled unit costs around $\$ 850$. Around $61 \%$ of the total costs is carried by the particle monitor and the printed circuit board assembly. These two are the key production components that can be targeted in the future, with intention of reducing the overall cost of the air quality feedback system.

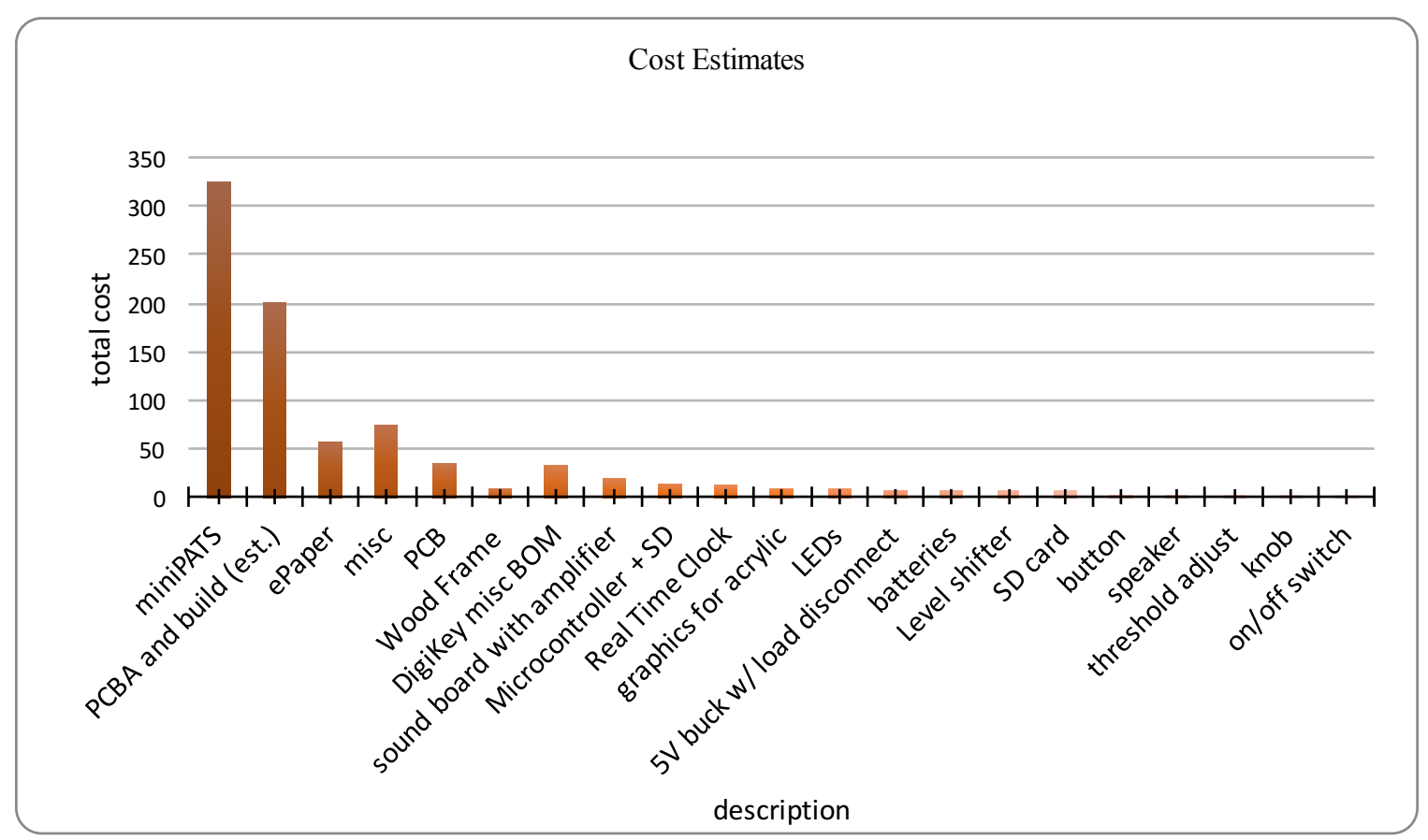

Figure 12: Cost estimates for a unit feedback system (Estimates by Dr. Danny Wilson) 


\section{Chapter 9: Experimental Data}

For the purpose of understanding $\mathrm{PM}_{2.5}$ emissions from biomass stoves, an air quality model was developed to study how indoor $\mathrm{PM}_{2.5}$ levels from an EcoZoom wood stove change over time.

\subsection{Experiment description}

The experiment was conducted in a laboratory fume hood with the following characteristics:

Table 3: Experiment environment characteristics

\begin{tabular}{|l|l|l|}
\hline Parameter & Value & Unit \\
\hline Face velocity & 0.508 & $\mathrm{~m} / \mathrm{sec}$ \\
\hline Opening area & 0.157 & $\mathrm{~m}^{2}$ \\
\hline Ventilation rate & 0.079756 & $\mathrm{~m}^{3} / \mathrm{sec}$ \\
\hline Volume & 1.07545 & $\mathrm{~m}^{3}$ \\
\hline
\end{tabular}

The following assumptions were made:

- The fume hood contains a constant air volume (see Eq. 3 and Table 3) and the air is well mixed.

The experimental system governing equations for the mass of $\mathrm{PM}_{2.5}$ are:

○ System flow balance equation:

$$
\text { Qin }=\text { Qout }=Q \quad(\text { Eq. 3) }
$$

○ System mass balance equation:

$$
\frac{d C}{d T}=\frac{Q_{\text {in }} * C_{i n}}{V}-\frac{Q_{o u t} * C}{V}+\frac{S}{V} \quad(E q .4)
$$

where $\frac{d C}{d T}$ is the change in concentration of $\mathrm{PM}_{2.5}$ with time, $Q_{i n}$ and $Q_{o u t}$ are the flow rate 
of air entering and leaving the fume hood respectively, $C_{\text {in }}$ is the concentration of $\mathrm{PM}_{2.5}$ entering the fume hood, $V$ is the volume of the fume hood, $C$ is the concentration of $\mathrm{PM}_{2.5}$ in the fume hood, and $S$ is the source term representing emissions from the stove (see Figure 13 ).

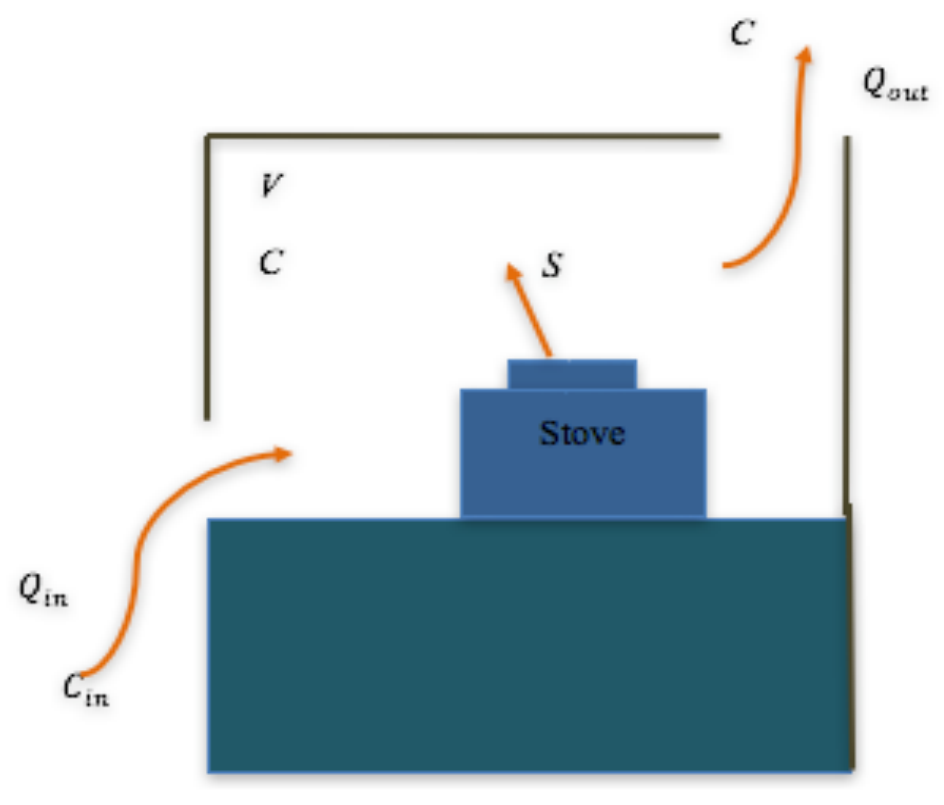

Figure 13: Experimental Fume Hood Diagram

The numerical solution to the system mass balance equation (Eq. 4) is:

$$
C^{t+1}=C^{t}+\left(\frac{\Delta t * Q_{\text {in }} * C_{\text {in }}}{V}\right)-\left(\frac{\Delta t * Q_{o u t} * C^{t}}{V}\right)+\left(\frac{\Delta t * S^{t}}{V}\right) \quad(E q .5)
$$

Where $\mathrm{t}$ is a given time at which concentrations are measured and $\Delta \mathrm{t}$ is the time interval between measurements.

In this experiment, an EcoZoom biomass stove was placed in the fume hood and used to burn average soft wood (conifer) sticks. A particulate monitor was installed in the 
fume hood, 50 centimeters to the right of the stove, and 23 centimeters above the stove (see Figure 14).

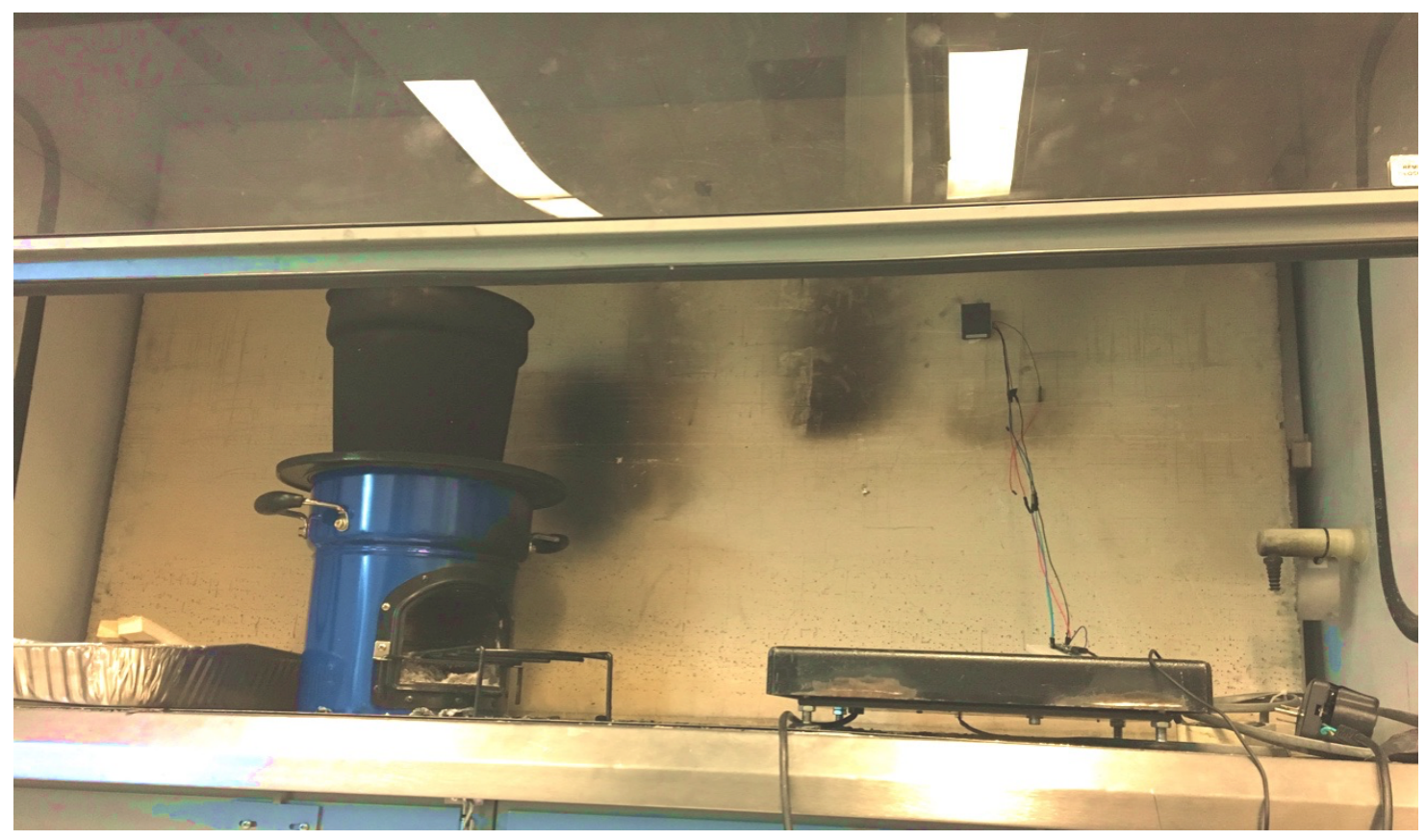

Figure 14: Experiment environment. Fume hood with EcoZoom stove (left) and particle monitor (right)

The particle monitor used is the Honeywell laser-based particle sensor. The sensor uses light scattering method to detect and compute particulate matter concentration in a given environment and has an accuracy range of $+/-15 \%$ and does not output PM2.5 concentrations above $1000 \mu \mathrm{g} / \mathrm{m}^{3}$. 


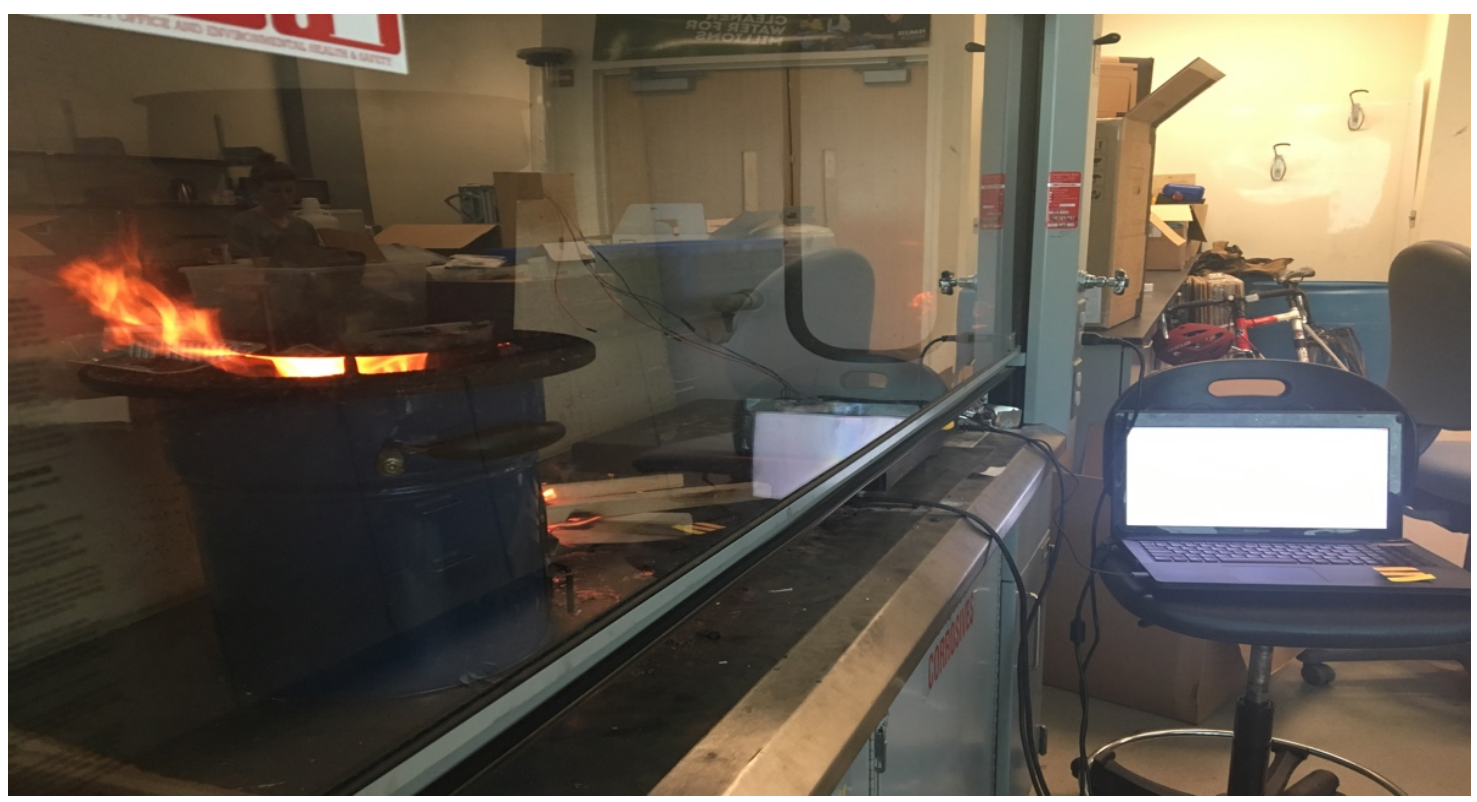

Figure 15: Experiment in progress

Figure 15 shows the experiment in progress. The EcoZoom stove is fed with conifer sticks and $\mathrm{PM}_{2.5}$ levels are measured at 5 second time intervals.

\subsection{Analysis of experimental data}

Graphical representation of measured $\mathrm{PM}_{2.5}$ concentrations allowed graphical identification of cooking events (see Figure 16). Starting fire results in clear spikes in $\mathrm{PM}_{2.5}$ levels. These levels fluctuate with cleaner air entering the fume hood and polluted exiting the fume hood. 


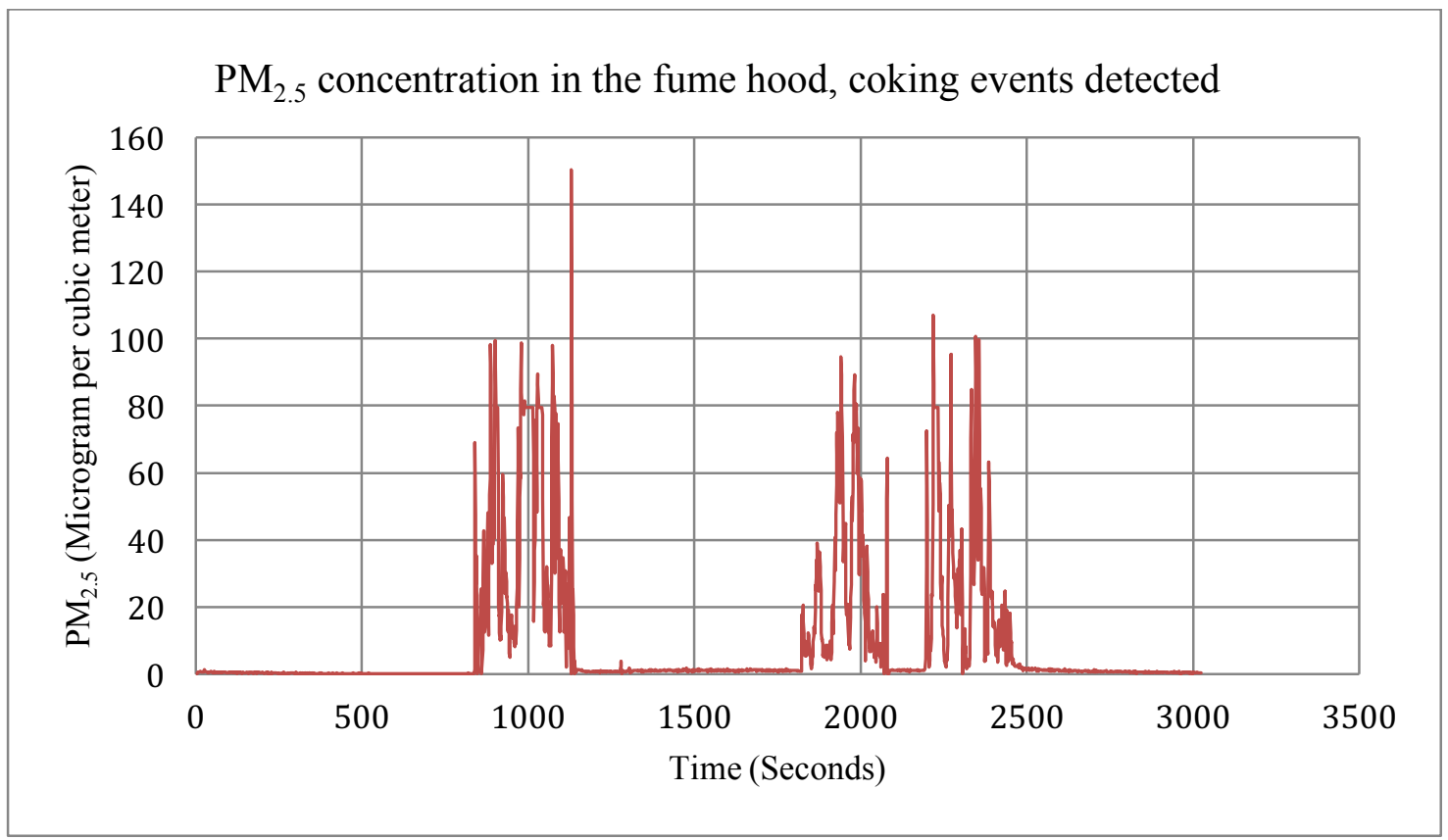

Figure 16: PM2.5 concentration in the fume hood over 4 hours and 11 minutes of running experiment

\subsection{Numerical Model with time variable emissions}

The solution to the general mass balance equation (Eq. 5) was used to set up a numerical model in Excel for $\mathrm{PM}_{2.5}$ emissions during one cooking event.

Rearranging the Eq. 5 gives an expression of the time variable emissions (Eq. 6) from the EcoZoom stove:

$$
s^{t}=\left[c^{t+1}-c^{t}-\left(\frac{\Delta t * Q_{i n} * C_{i n}}{V}\right)+\left(\frac{\Delta t * Q_{o u t} * C^{t}}{V}\right)\right] * \frac{V}{\Delta t} \quad(E q .6)
$$

The numerical model of $\mathrm{PM}_{2.5}$ emissions shows the average mass emitted per unit time to be $34 \mu \mathrm{g} / \mathrm{sec}$ (see Figure 17). This value is approximately 8 times lower that the EPA mandatory smoke emissions limits for wood stoves, which also include $\mathrm{PM}_{10}$ and larger particles. 


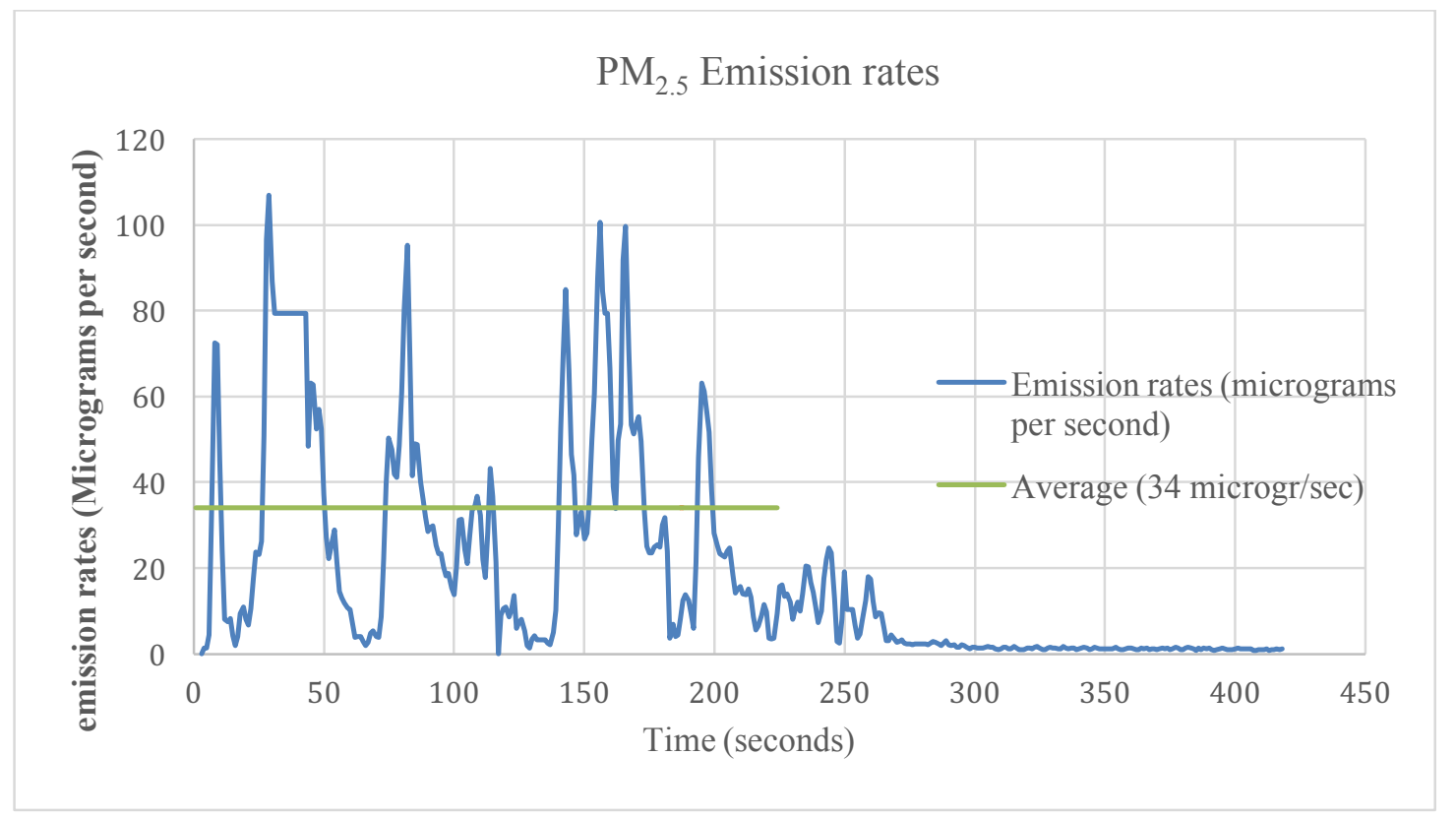

Figure 17: Modeled time variable emissions over time

\subsection{Analytical Model with constant emissions}

The computed average emissions value was used to model how concentrations change over time. The analytical model (Eq. 7) assumes that emissions are constant over time.

$$
C^{t}=\left[\frac{\left(\frac{S}{V}\right)+\left(C_{i n} \cdot \frac{Q}{V}\right)}{\frac{Q}{V}}\right]\left[1-e^{-(Q / V) t}\right]+C_{0} e^{-(Q / V) t} \quad(E q .7)
$$

Where $C_{0}$ is the $\mathrm{PM}_{2.5}$ concentration in the fume hood at the beginning (i.e. at time $=0$ ) 


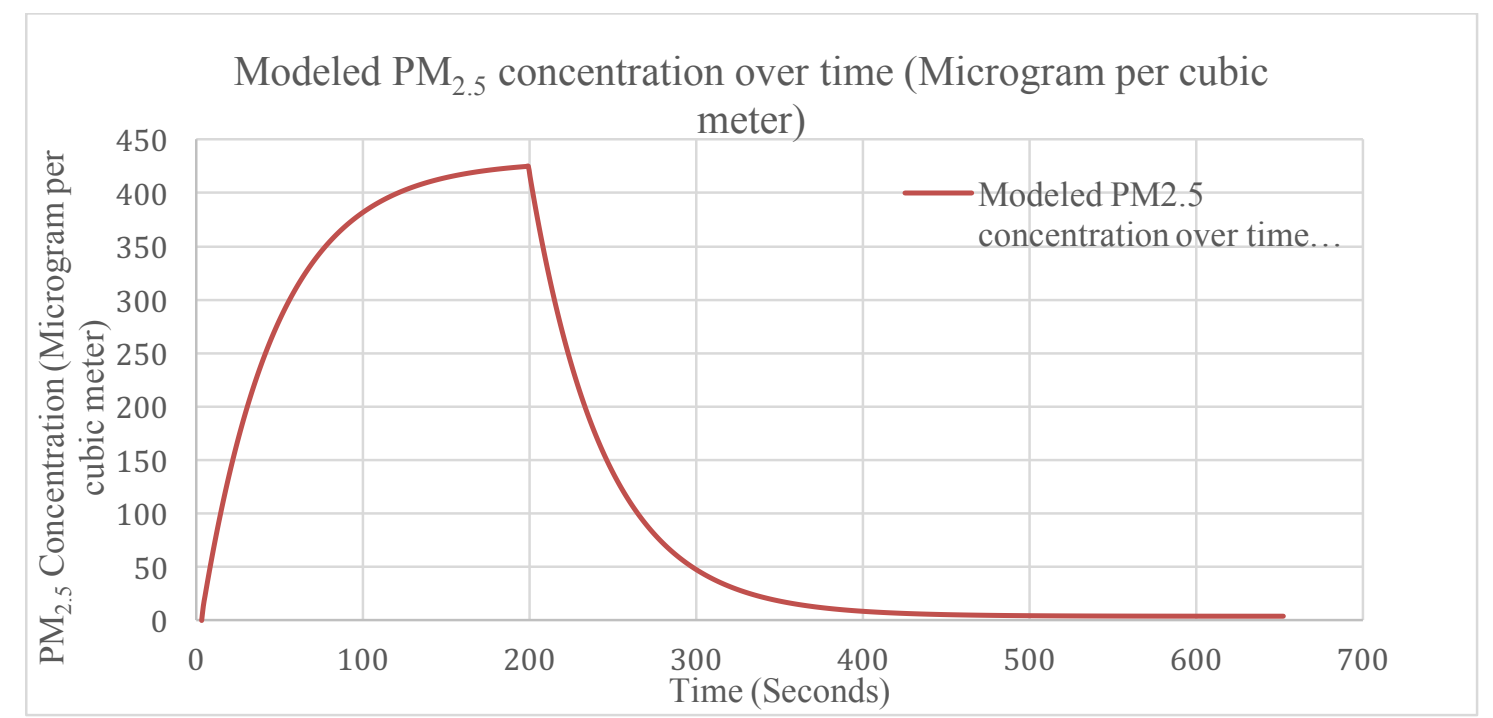

Figure 18: Modeled $P M_{2.5}$ concentration over time

The analytical model shows it takes 5 minutes and 32 seconds for $\mathrm{PM}_{2.5}$ concentration in the fume hood to go back to the initial concentration of $4 \mu \mathrm{g} / \mathrm{m}^{3}$, after emission sources from the stove have been eliminated (see Figure 18).

Figure 5. shows the model fit to experimental data. The fit is rough during the time when wood is being fed to the stove (see Figure 19), because lifting the fume hood cover causes irregularities in air flow that destabilize the system. The fit is smother during the stove shut down phase. 


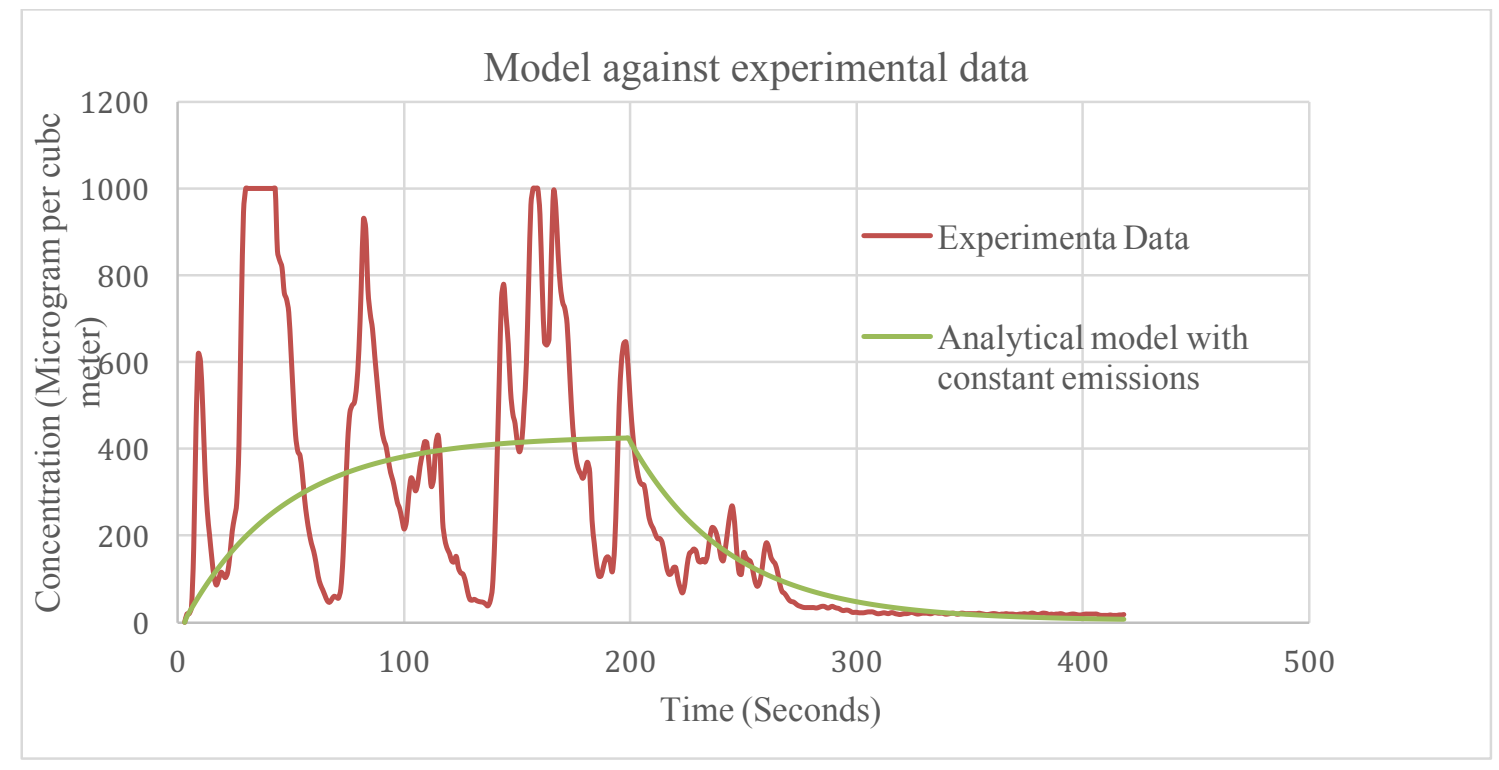

Figure 19: Fitting of analytical model to experimental data

This model shows sensitivity to ventilation rates. Doubling the ventilation rate reduces that time to less than half ( $2 \mathrm{~min}, 41$ seconds). With a ventilation rate of 0.036 $\mathrm{m}^{3} / \mathrm{sec}$ (recommended home ventilation rate) (Parajuli et al. 2016), assuming a 5-person family - average Rwandan family size - (Temel 2011), it takes 11 minutes and 38 seconds for $\mathrm{PM}_{2.5}$ levels to drop back to the initial concentration (see Figure 20).

If the initial concentration was $25 \mu \mathrm{g} / \mathrm{m}^{3}$ - WHO standards $\mathrm{PM}_{2.5}$ levels 24-hour average limit -, starting the EcoZoom stove would raise the concentration to $1133 \mu \mathrm{g} / \mathrm{m}^{3}$ in 59 seconds and it would take 17 minutes to get $\mathrm{PM}_{2.5}$ levels back to $25 \mu \mathrm{g} / \mathrm{m}^{3}$ after stopping the stove. 


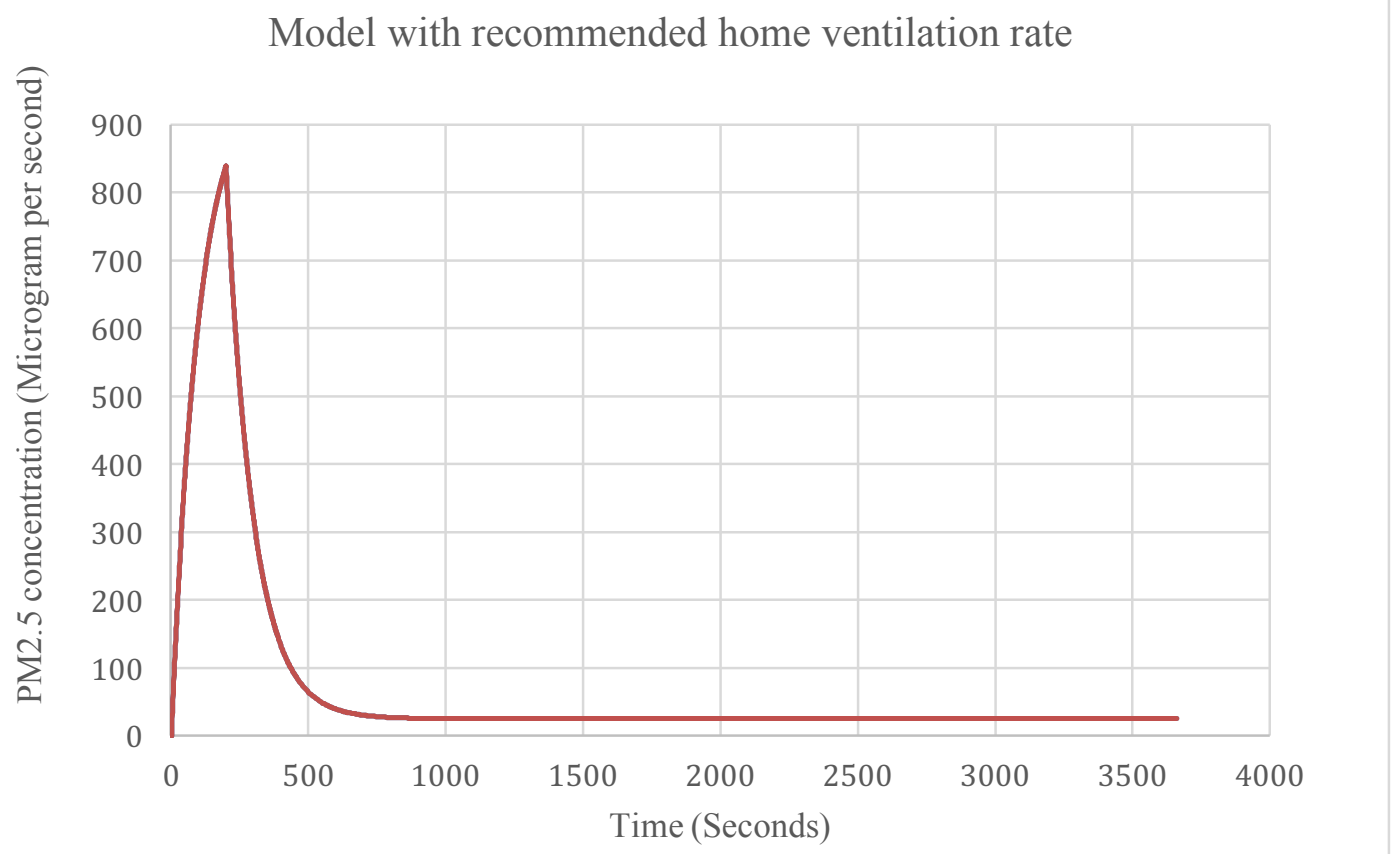

Figure 20: $P M_{2.5}$ concentration modeling under recommended ventilation conditions 


\section{Chapter 10: Conclusion}

Clean cooking considerably reduces household air pollution, thus alleviating the impact of household air pollution on health. However, studies show that those benefits can only be achieved when clean cooking is practiced exclusively, thus the justification for this thesis and the need for more efforts to implement interventions that address stovestacking issues and promote clean cooking.

This thesis presents the design of an air quality feedback system that promotes exclusive use of LPG cookstoves, by providing real time air quality data to users and providing warning alarms in the event of biomass cookstove use. The air quality feedback system was designed in close consultation with women in Rwanda who are the primary cook for their families and who meet the criteria for the HAPIN Trial LPG cookstoves and fuel intervention participants.

Based on the results from interviews, group discussion and other HCD activities conducted and detailed in this thesis, the developed audio-visual feedback display provides a user-friendly, context-specific, acceptable, realistic and viable way of delivering air quality and LPG cookstove exclusive use feedback to LPG cookstove users. This feedback system may result in sustained and exclusive LPG cookstove use, reduced household air pollution and increased health benefits from clean cooking.

The experimental method described in this thesis, may be used to calibrate the air quality feedback alarm. The developed models may be used to determine concentration at which the alarm should go on and off, and to predict the approximate time the alarm will stay on, after the biomass stoves are shut down. 
The resulting product will be installed in 100 households that are part of the HAPIN Trial.

One challenge encountered during this research was that there was limited literature on similar HCD-focused environmental engineering work. One lesson learned is not to rush HCD consultation activities. Although we believe we got enough information from potential users to inform design of the air quality feedback system, we believe it would have been beneficial to plan several HCD sessions during different stages of the product development. For instance, getting feedback from the users on the final prototype, before assembly and final production work is done, may useful towards fixing issues designers might have missed and ensuring success of the product. 


\section{Future work}

The audio-visual air quality feedback display, product of the HDC work described in this thesis will be deployed in Rwanda in the summer of 2018, to conduct a sub-study of the HAPIN trial aiming at assessing the impact of visual and audio personalized feedback on LPG cookstove adoption, and investigating how indoor PM2.5 correlate to health outcomes, among other objectives.

100 households in Rwanda will be enrolled in this sub-study for a period of 12 months and we will seek feedback from them to inform further improvements of the feedback system.

There will be perception survey at installation and evaluation/feedback survey at the end of the study, to understand how user interacted with the feedback system and what further improvements can be implemented. 


\section{Work Cited}

Austin, Kelly F., and Maria Theresa Mejia. 2017. "Household Air Pollution as a Silent Killer: Women's Status and Solid Fuel Use in Developing Nations." Population and Environment 39 (1): 1-25.

Barstow, Christina K., Corey L. Nagel, Thomas F. Clasen, and Evan A. Thomas. 2016. "Process Evaluation and Assessment of Use of a Large-Scale Water Filter and Cookstove Program in Rwanda." BMC Public Health 16 (July): 584.

Bazzano, Alessandra N., Jane Martin, Elaine Hicks, Maille Faughnan, and Laura Murphy. 2017. "Human-Centred Design in Global Health: A Scoping Review of Applications and Contexts." PloS One 12 (11): e0186744.

Boy, Erick, Nigel Bruce, and Hernán Delgado. 2002. "Birth Weight and Exposure to Kitchen Wood Smoke during Pregnancy in Rural Guatemala." Environmental Health Perspectives 110 (1): 109-14.

Brook, Robert D., Sanjay Rajagopalan, C. Arden Pope 3rd, Jeffrey R. Brook, Aruni Bhatnagar, Ana V. Diez-Roux, Fernando Holguin, et al. 2010. "Particulate Matter Air Pollution and Cardiovascular Disease: An Update to the Scientific Statement from the American Heart Association." Circulation 121 (21): 2331-78.

Brown, T. and J. Wyatt. 2010. "Design Thinking for Social Innovation.” Stanford Social Innovation Review, Winter.

Bruce, N., R. Perez-Padilla, and R. Albalak. 2000. "Indoor Air Pollution in Developing Countries: A Major Environmental and Public Health Challenge." Bulletin of the World Health Organization 78 (9): 1078-92.

Brunekreef, Bert, and Stephen T. Holgate. 2002. "Air Pollution and Health." The Lancet 360 (9341): 1233-42.

Calderón-Garcidueñas, L., E. Leray, P. Heydarpour, R. Torres-Jardón, and J. Reis. 2016. "Air Pollution, a Rising Environmental Risk Factor for Cognition, Neuroinflammation and Neurodegeneration: The Clinical Impact on Children and beyond." Revue Neurologique 172 (1): 69-80.

El Tayeb Muneer, Siddig, and El Waseilah Mukhtar Mohamed. 2003. "Adoption of Biomass Improved Cookstoves in a Patriarchal Society: An Example from Sudan." The Science of the Total Environment 307 (1-3): 259-66.

Emory University Rollins School of Public Health. 2018. "HAPIN Trial: About the HAPIN Trial.” Accessed July 20, 2018. https:/www.hapintrial.org/about.html.

Gall, Elliott T., Ellison M. Carter, C. Matt Earnest, and Brent Stephens. 2013. "Indoor Air Pollution in Developing Countries: Research and Implementation Needs for Improvements in Global Public Health." American Journal of Public Health 103 (4): e67-72.

Genc, Sermin, Zeynep Zadeoglulari, Stefan H. Fuss, and Kursad Genc. 2012. "The Adverse Effects of Air Pollution on the Nervous System." Journal of Toxicology 2012 (February): 782462.

Gifford, M. L. 2010. “A Global Review of Cookstove Programs (Master's Dissertation).” 
Haberer, Jessica E., Angella Musiimenta, Esther C. Atukunda, Nicholas Musinguzi, Monique A. Wyatt, Norma C. Ware, and David R. Bangsberg. 2016. "Short Message Service (SMS) Reminders and Real-Time Adherence Monitoring Improve Antiretroviral Therapy Adherence in Rural Uganda." AIDS 30 (8): 1295-1300.

Hohm, Charles F. 1976. "A Human-Ecological Approach to the Reality and Perception of Air Pollution: The Los Angeles Case.” Pacific Sociological Review 19 (1): 21-44.

Institute for Health Metrics and Evaluation. 2015. "GBD Compare." Accessed July 5, 2018. https://vizhub.healthdata.org/gbd-compare/.

Johnson, Michael A., and Ranyee A. Chiang. 2015. "Quantitative Guidance for Stove Usage and Performance to Achieve Health and Environmental Targets."

Environmental Health Perspectives 123 (8): 820-26.

Klepeis, Neil E., Suzanne C. Hughes, Rufus D. Edwards, Tracy Allen, Michael Johnson, Zohir Chowdhury, Kirk R. Smith, Marie Boman-Davis, John Bellettiere, and Melbourne F. Hovell. 2013. "Promoting Smoke-Free Homes: A Novel Behavioral Intervention Using Real-Time Audio-Visual Feedback on Airborne Particle Levels." PloS One 8 (8): e 73251.

Kolko, Jon. 2015. "Design Thinking Comes of Age." Harvard Business Review 93 (9): $66-71$.

Legros, Gwenaelle, Ines Havet, Nigel Bruce, Sophie Bonjour, Kamal Rijal, Minoru Takada, and Others. 2009. "The Energy Access Situation in Developing Countries: A Review Focusing on the Least Developed Countries and Sub-Saharan Africa." New York: United Nations Development Programme and World Health Organization.

Lim, Stephen S., Theo Vos, Abraham D. Flaxman, Goodarz Danaei, Kenji Shibuya, Heather Adair-Rohani, Markus Amann, et al. 2012. "A Comparative Risk Assessment of Burden of Disease and Injury Attributable to 67 Risk Factors and Risk Factor Clusters in 21 Regions, 1990-2010: A Systematic Analysis for the Global Burden of Disease Study 2010." The Lancet 380 (9859): 2224-60.

Marge, Euei-Pdf Gtz. 2009. "Biomass Energy Strategy (BEST), Rwanda.” EU Energy Initiative Partnership Dialogue Facility, Eschborn.

Martin, Seth S., David I. Feldman, Roger S. Blumenthal, Steven R. Jones, Wendy S. Post, Rebeccah A. McKibben, Erin D. Michos, et al. 2015. "mActive: A Randomized Clinical Trial of an Automated mHealth Intervention for Physical Activity Promotion." Journal of the American Heart Association 4 (11). https://doi.org/10.1161/JAHA.115.002239.

Matheson, Gordon O., Chris Pacione, Rebecca K. Shultz, and Martin Klügl. 2015. "Leveraging Human-Centered Design in Chronic Disease Prevention." American Journal of Preventive Medicine 48 (4): 472-79.

National Institutes of Health. 2018. "Common Fund Programs: HAPIN - Program Resources.” Accessed July 20, 2018. https://commonfund.nih.gov/globalhealth/hapinresources.

Parajuli, Indira, Heekwan Lee, and Krishna Raj Shrestha. 2016. "Indoor Air Quality and Ventilation Assessment of Rural Mountainous Households of Nepal." International Journal of Sustainable Built Environment 5 (2): 301-11. 
Pickett, Anna Ruth, and Michelle L. Bell. 2011. "Assessment of Indoor Air Pollution in Homes with Infants." International Journal of Environmental Research and Public Health 8 (12): 4502-20.

Pope, C. Arden, 3rd, Richard T. Burnett, Michael J. Thun, Eugenia E. Calle, Daniel Krewski, Kazuhiko Ito, and George D. Thurston. 2002. "Lung Cancer, Cardiopulmonary Mortality, and Long-Term Exposure to Fine Particulate Air Pollution." JAMA: The Journal of the American Medical Association 287 (9): 113241.

Rabbi, Mashfiqui, Angela Pfammatter, Mi Zhang, Bonnie Spring, and Tanzeem Choudhury. 2015. "Automated Personalized Feedback for Physical Activity and Dietary Behavior Change with Mobile Phones: A Randomized Controlled Trial on Adults." JMIR mHealth and uHealth 3 (2): e42.

Reagan, Ian J., James P. Bliss, Ron Van Houten, and Bryan W. Hilton. 2013. "The Effects of External Motivation and Real-Time Automated Feedback on Speeding Behavior in a Naturalistic Setting." Human Factors 55 (1): 218-30.

Rodbard, David, Timothy Bailey, Lois Jovanovic, Howard Zisser, Roy Kaplan, and Satish K. Garg. 2009. "Improved Quality of Glycemic Control and Reduced Glycemic Variability with Use of Continuous Glucose Monitoring." Diabetes Technology \& Therapeutics 11 (11): 717-23.

Rosenthal, Joshua, Kalpana Balakrishnan, Nigel Bruce, David Chambers, Jay Graham, Darby Jack, Lydia Kline, et al. 2017. "Implementation Science to Accelerate Clean Cooking for Public Health.” Environmental Health Perspectives 125 (1): A3-7.

Ruiz-Mercado, Ilse, Omar Masera, Hilda Zamora, and Kirk R. Smith. 2011. "Adoption and Sustained Use of Improved Cookstoves.” Energy Policy 39 (12): 7557-66.

Semenza, Jan C., Daniel J. Wilson, Jeremy Parra, Brian D. Bontempo, Melissa Hart, David J. Sailor, and Linda A. George. 2008. "Public Perception and Behavior Change in Relationship to Hot Weather and Air Pollution." Environmental Research 107 (3): 401-11.

Stieb, David M., Li Chen, Maysoon Eshoul, and Stan Judek. 2012. “Ambient Air Pollution, Birth Weight and Preterm Birth: A Systematic Review and MetaAnalysis." Environmental Research 117 (August): 100-111.

Stuckey, Melanie I., Shawn W. Carter, and Emily Knight. 2017. "The Role of Smartphones in Encouraging Physical Activity in Adults." International Journal of General Medicine 10 (September): 293-303.

Temel, Tugrul. 2011. "Family Size, Human Capital and Growth: Structural Path Analysis of Rwanda." Available online: https://mpra.ub.uni-muenchen.de/31741/.

Thomas, Emma, Kremlin Wickramasinghe, Shanthi Mendis, Nia Roberts, and Charlie Foster. 2015. "Improved Stove Interventions to Reduce Household Air Pollution in Low and Middle-Income Countries: A Descriptive Systematic Review." BMC Public Health 15 (July): 650.

Thomas, Evan A., Sarita Tellez-Sanchez, Carson Wick, Miles Kirby, Laura Zambrano, Ghislaine Abadie Rosa, Thomas F. Clasen, and Corey Nagel. 2016. "Behavioral Reactivity Associated with Electronic Monitoring of Environmental Health 
Interventions: A Cluster Randomized Trial with Water Filters and Cookstoves." Environmental Science \& Technology 50 (7): 3773-80.

Thurston, George D., Howard Kipen, Isabella Annesi-Maesano, John Balmes, Robert D. Brook, Kevin Cromar, Sara De Matteis, et al. 2017. "A Joint ERS/ATS Policy Statement: What Constitutes an Adverse Health Effect of Air Pollution? An Analytical Framework." The European Respiratory Journal: Official Journal of the European Society for Clinical Respiratory Physiology 49 (1). https://doi.org/10.1183/13993003.00419-2016.

Várhegyi, Gábor, Zoltán Sebestyén, Zsuzsanna Czégény, Ferenc Lezsovits, and Sándor Könczöl. 2012. "Combustion Kinetics of Biomass Materials in the Kinetic Regime." Energy \& Fuels: An American Chemical Society Journal 26 (2): 1323-35.

Vechakul, Jessica, Bina Patel Shrimali, and Jaspal S. Sandhu. 2015. "Human-Centered Design as an Approach for Place-Based Innovation in Public Health: A Case Study from Oakland, California." Maternal and Child Health Journal 19 (12): 2552-59.

Wang, Xiaoming, Warren Kindzierski, and Padma Kaul. 2015. "Air Pollution and Acute Myocardial Infarction Hospital Admission in Alberta, Canada: A Three-Step Procedure Case-Crossover Study." PloS One 10 (7): e0132769.

Wickström, Gustav, and Tom Bendix. 2000. "The 'Hawthorne Effect'—what Did the Original Hawthorne Studies Actually Show?” Scandinavian Journal of Work, Environment \& Health, 363-67.

Yadama, Gautam N. 2013. Fires, Fuel, and the Fate of 3 Billion: The State of the Energy Impoverished. Oxford University Press.

Zhou, Zheng, Kathie L. Dionisio, Thiago G. Verissimo, Americo S. Kerr, Brent Coull, Stephen Howie, Raphael E. Arku, et al. 2014. "Chemical Characterization and Source Apportionment of Household Fine Particulate Matter in Rural, Peri-Urban, and Urban West Africa.” Environmental Science \& Technology 48 (2): 1343-51. 


\section{Appendix A- Triggers identification cards}

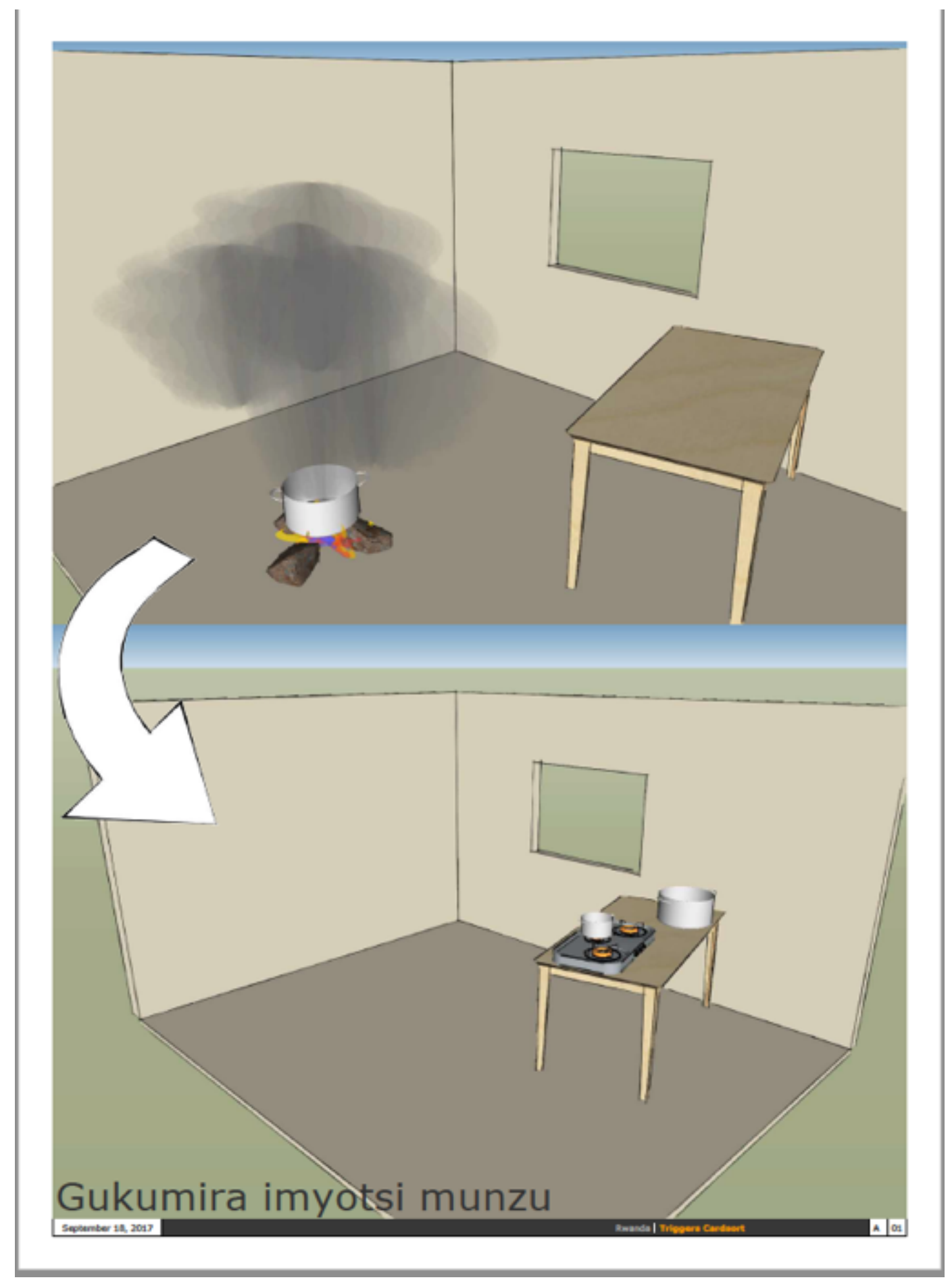




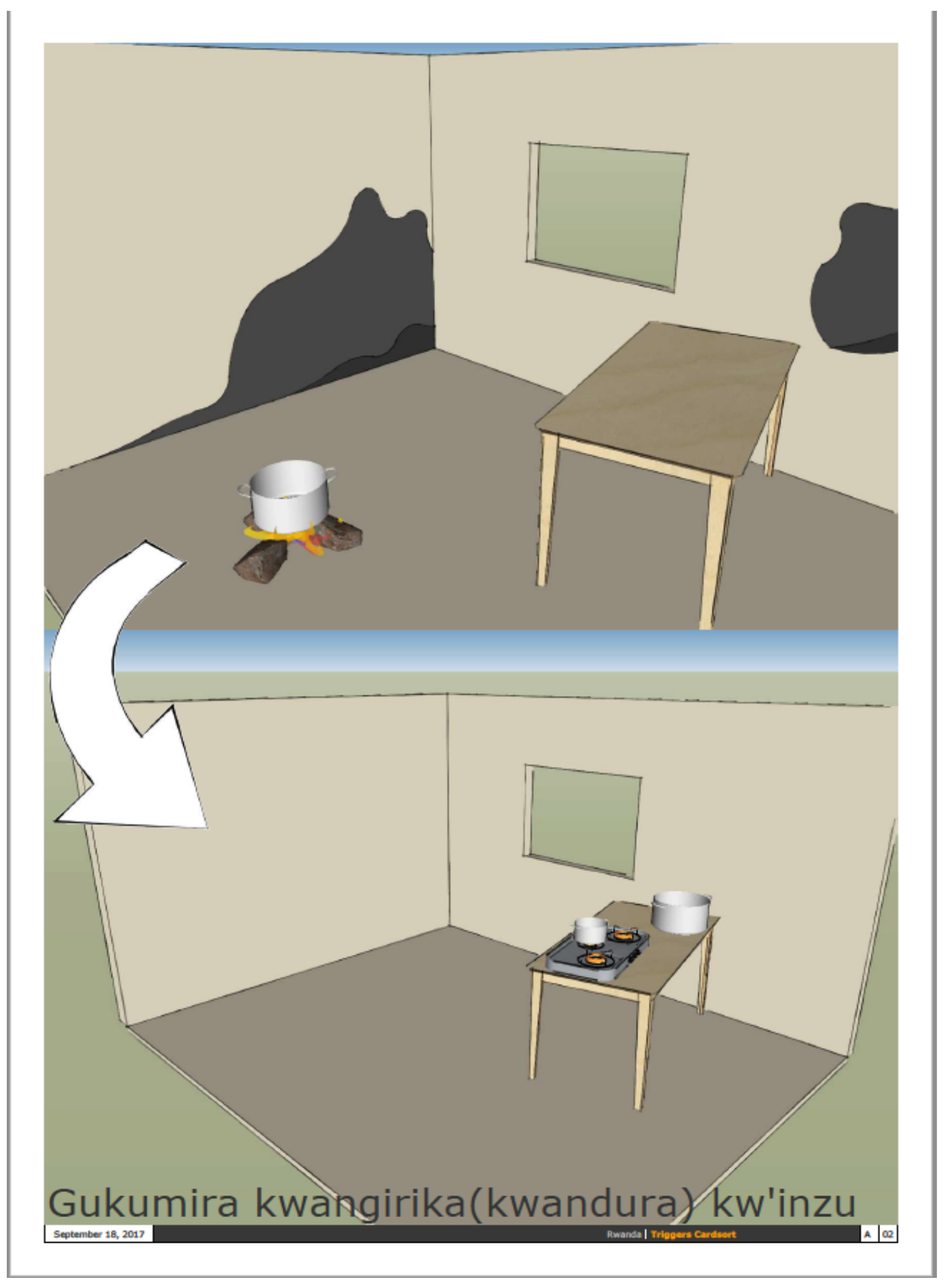




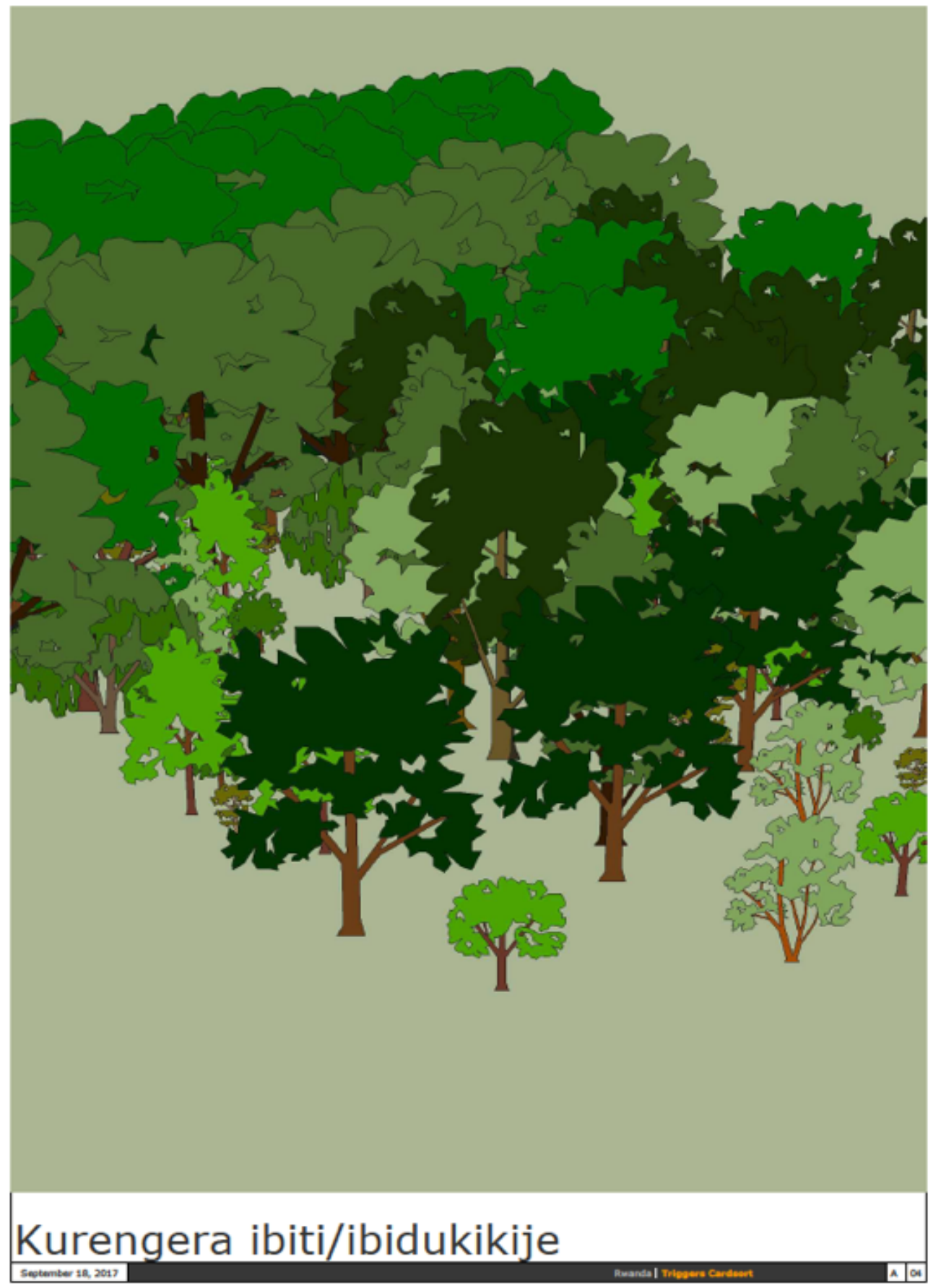




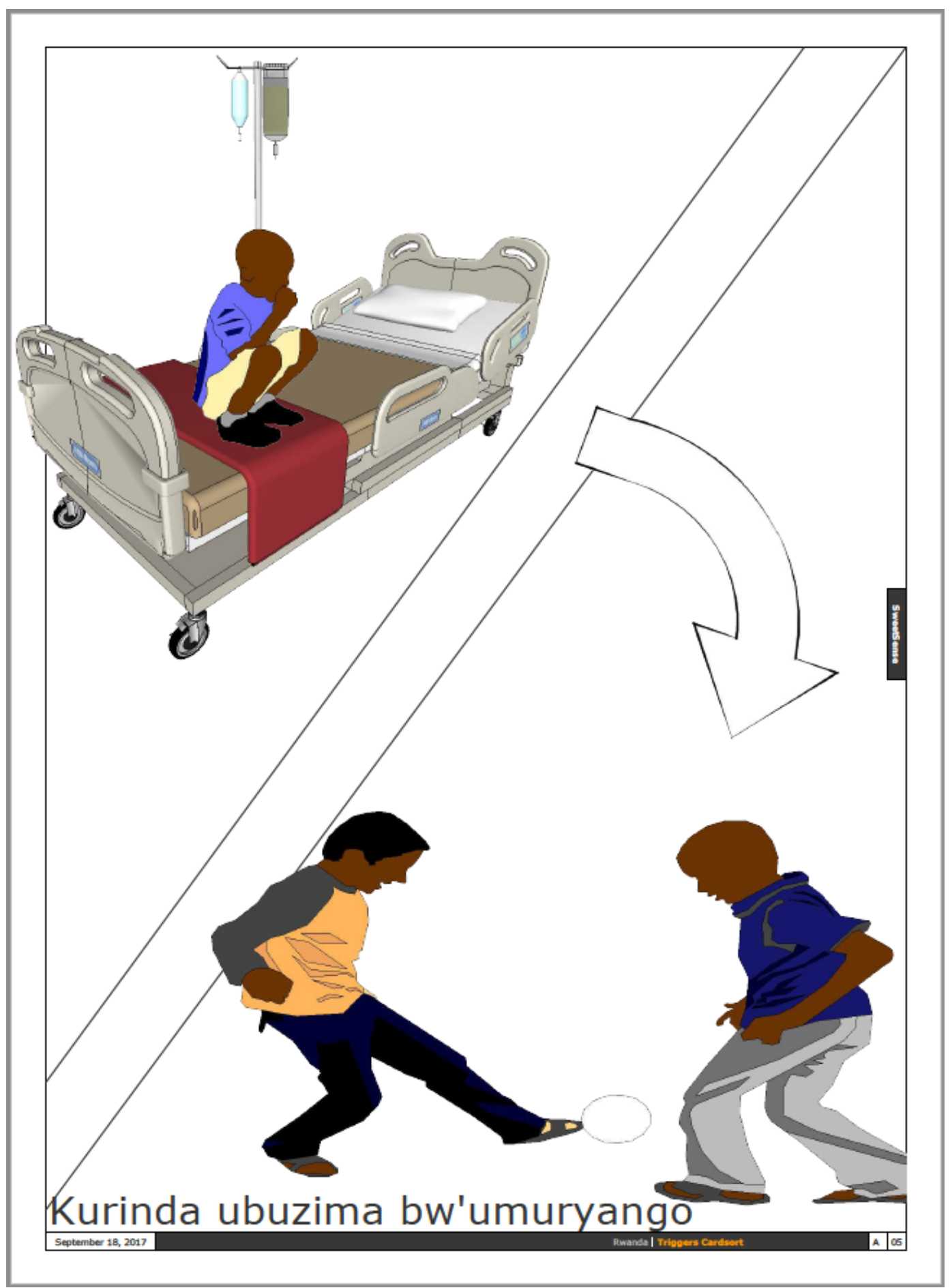




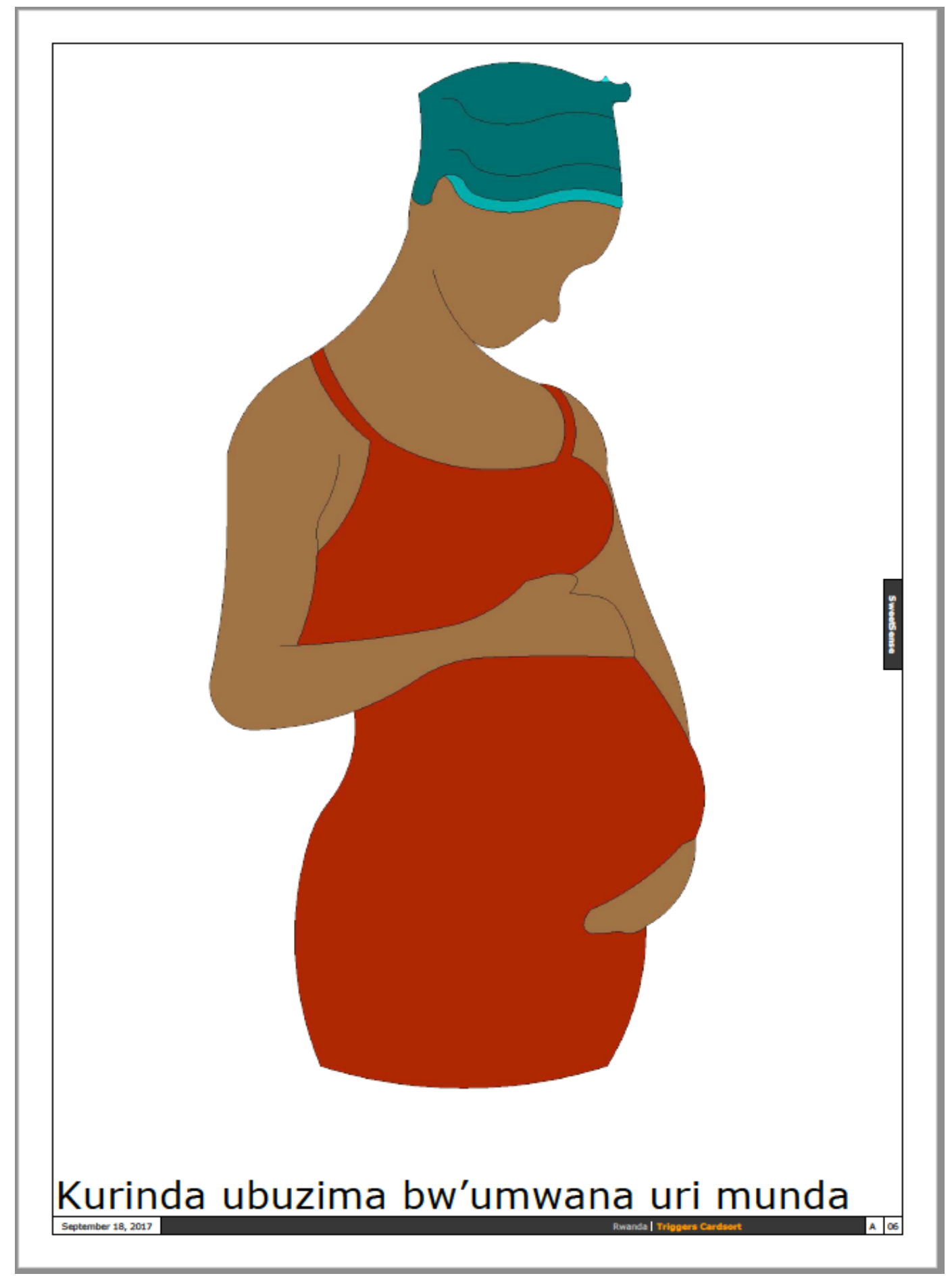




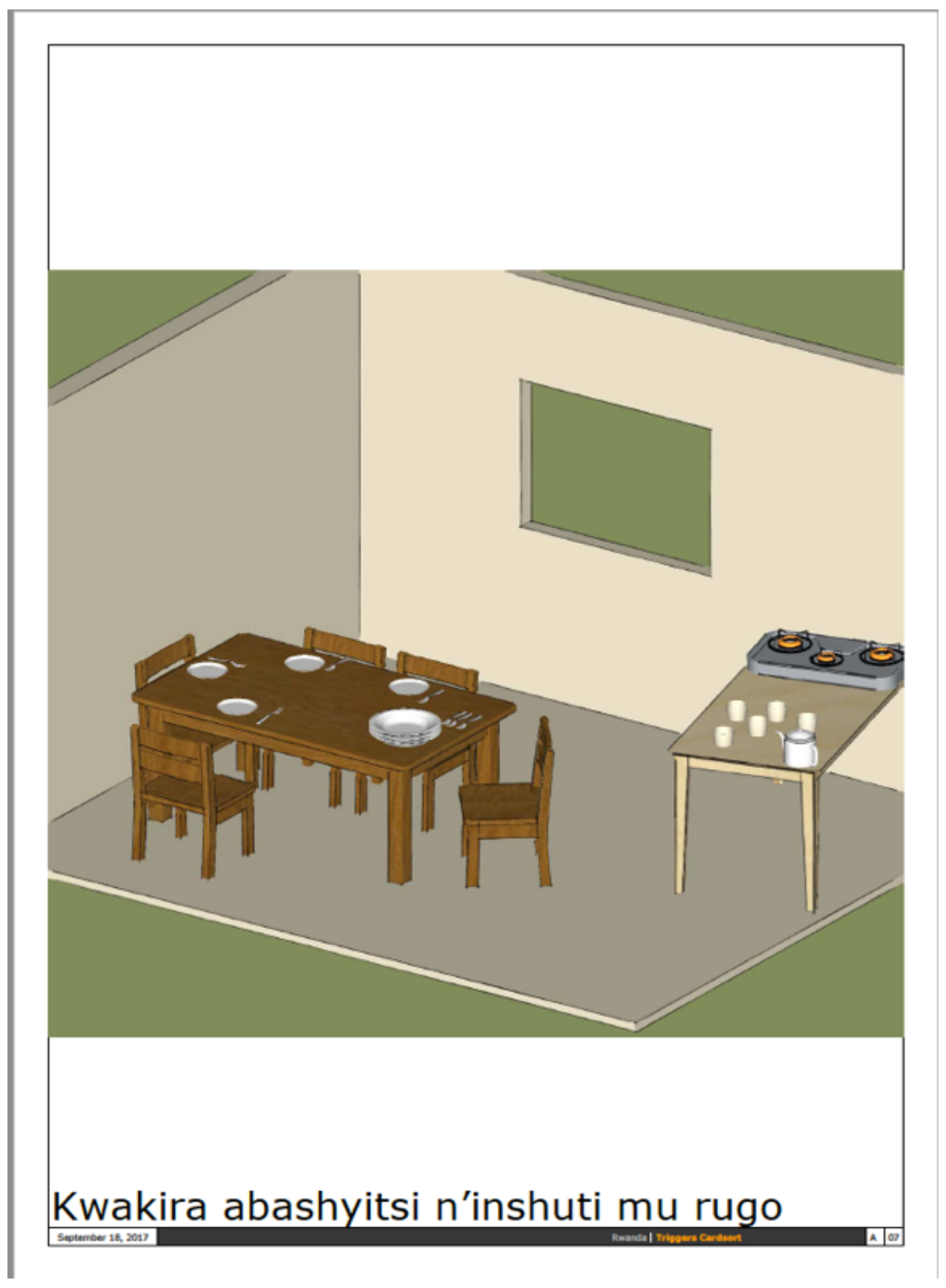


Appendix B- Feedback delivery means identification cards
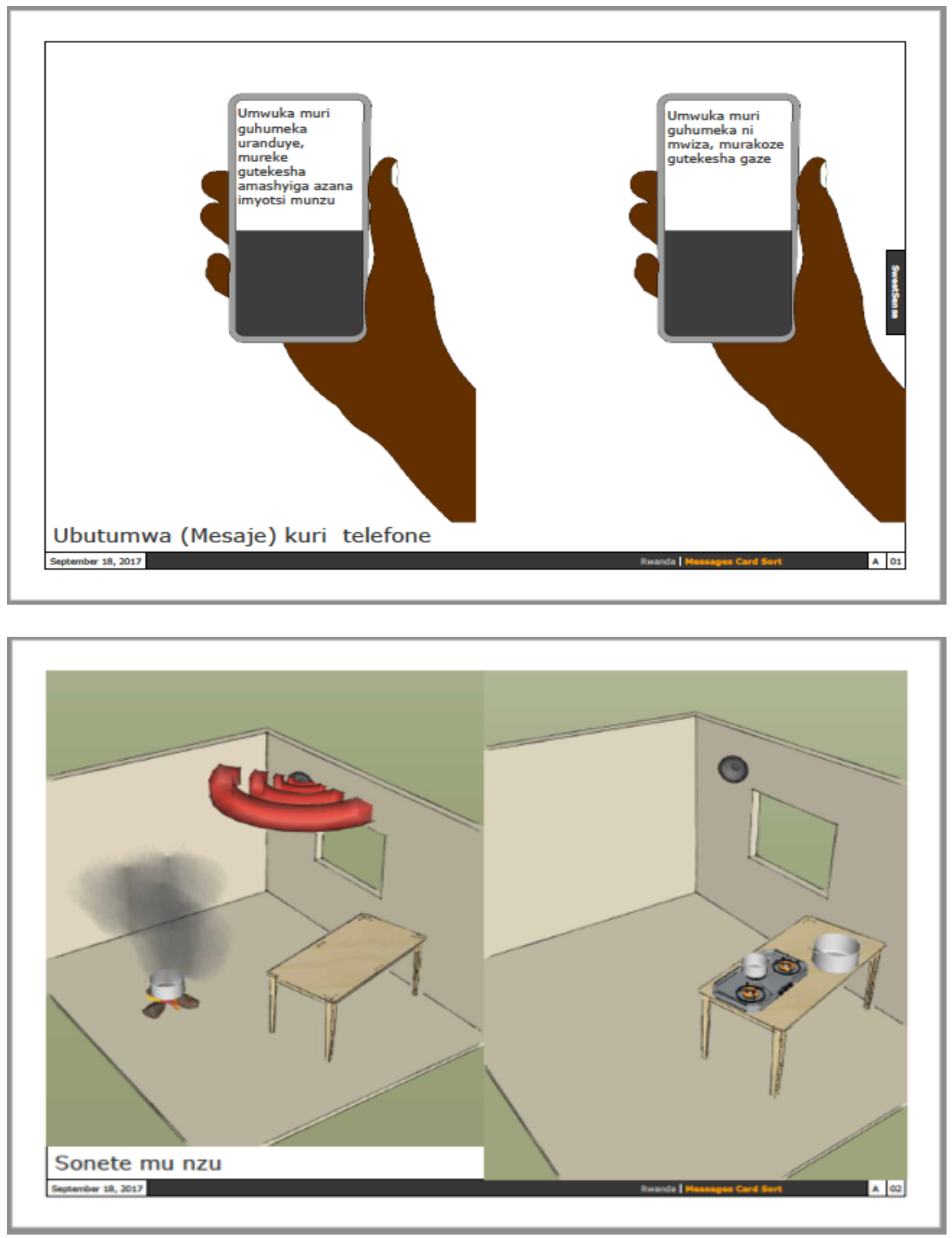

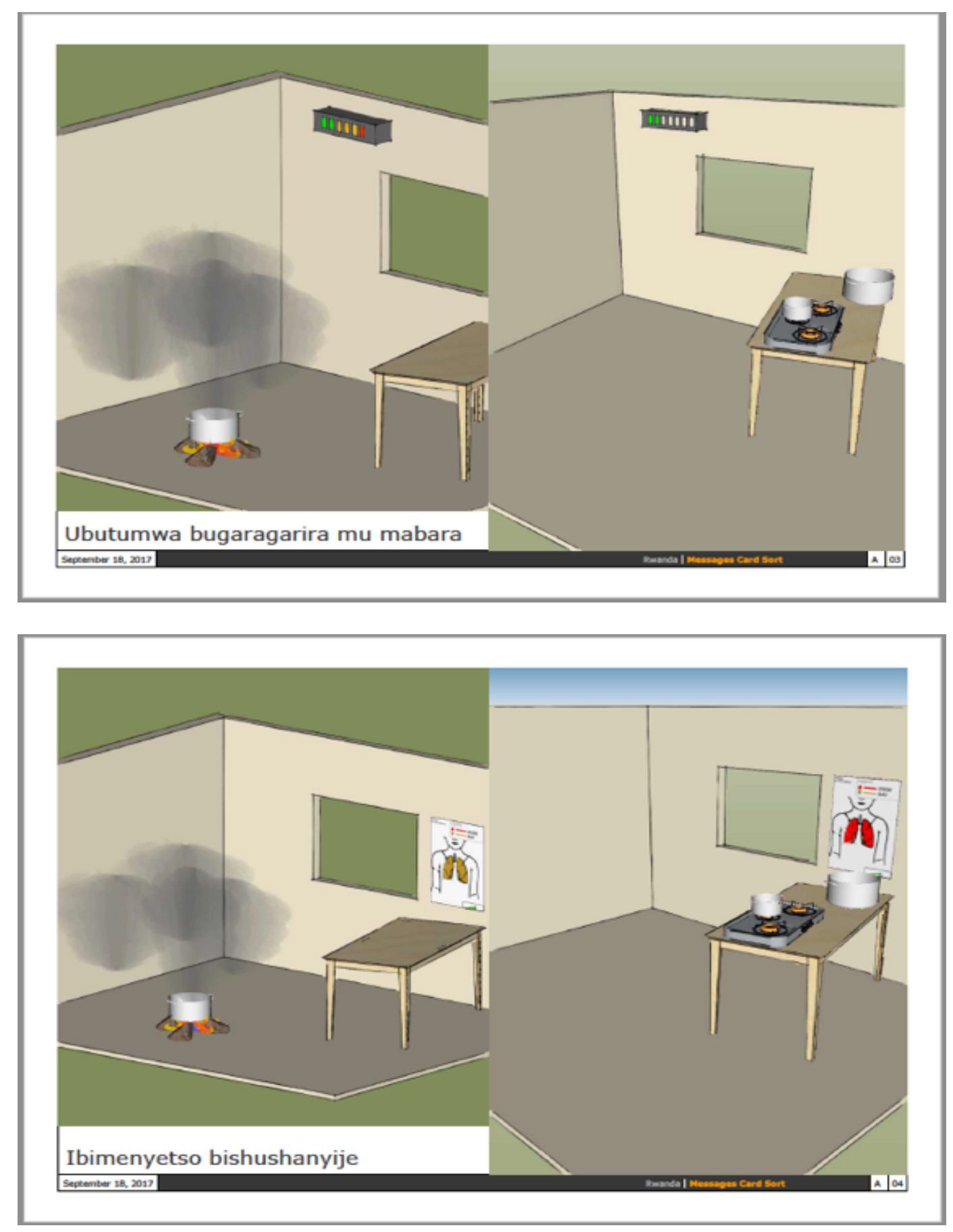


\section{Appendix C- Household interview questions}

a) LPG stove perception, pros and cons

Do you know about LPG stoves? (aspiration value, cleanliness, safety, how to get one...)

1. What do you know about LPG stoves?

2. What good thinks do you know about LPG stoves?

3. What are the challenges with LPG stoves?

4. Does your family have an LPG stove?

5. Where do you cook?

6. Under what circumstances do you use your traditional stove? (if they possess an LPG stove)

7. Where do you cook when using other stoves?

8. Do you ever cook outside? If yes, why? If no, why not?

9. What do you cook on LPG stove? What are the reasons why?

10. What do you cook on traditional stove? Why?

b) Triggers identification

1. We would like to know what is most important to you. Would you help us rank these cards, starting from what is most important? (provide them with the cards to sort) (Appendix A)

c) Message content and frequency

2. If you were to receive information/feedback on air quality status, how would you like 
to receive that information?

3. How often would you like to receive that information?

4. Who in the family do you think would like to have access to that information? Why?

d) Existing feedback techniques/methods

3. Do you receive feedback concerning your phone's airtime? What does it say? How about your phone's battery? What does it say? What does it look like? (get details about message features, sounds and colors) How about your network connectivity/strength? What does it say? What does it look like? Receipt of a message? Receipt of money through mobile money? missed call?

4. Do you receive any other similar information through your phone or other electronics, from other people other than your cell providers, family or friends? E.g. Community Health Workers

e) Existing features/sounds and colors

1. What colors communicate a specific message to you? What message do they communicate?

f) Test features/sounds and colors

1. What does the red color symbolize to you?

2. What does the green color symbolize to you?

3. What other colors mean something to you?

4. What does a thumb up mean to you?

5. What does a thumb down mean to you?

6. What other signs and features mean something to you? 


\section{Appendix D- Summary household interview answers}

10 women were interviewed in their homes and then brought together for a group discussion

Household interviews summarized outcomes

Background info

Two (2) of the respondents own LPG stoves, six (6) of them know about it and two (2) have heard about it.

Pros: Clean, cooks quickly, no smoke, easy to use, good for someone who needs to cook multiple times a day, kids can help cook, husband can help cook, saves time, no ash, can be anywhere, modern way of cooking, saves trees, charcoal is becoming expensive.

Cons: Explosion when not operated carefully, expensive, could hurt someone, inhaling gas can be a health issue, expensive (both gas and equipment), hard to replace parts.

Where they cook: 9 have a separate kitchen, 2 have an inside the house kitchen in addition to that, 1 person always cooks outside

Stove type: 2 use Rondereza only, 3 people use Rondereza + traditional stove, 1 uses Rondereza + traditional + charcoal and 2 use LPG + Rondereza + charcoal

Ever cook outside: 4 (yes), 5 (no) and 1 (void answer)

Tigers identification

\begin{tabular}{|c|c|c|c|c|c|c|}
\hline WEIGHT & Smoke & Walls & Trees & Kids & Infant & Friends \\
\hline 6 & 18 & 0 & 30 & 0 & 12 & 0 \\
\hline 5 & 10 & 10 & 0 & 20 & 5 & 0 \\
\hline 4 & 0 & 4 & 8 & 12 & 12 & \\
\hline 3 & 3 & 3 & 3 & 6 & 6 & \\
\hline 2 & 2 & 8 & 0 & 0 & 4 & \\
\hline 1 & 3 & 2 & 2 & 1 & 0 & \\
\hline SUM & 36 & 27 & 43 & 39 & 39 & \\
\hline
\end{tabular}


During the group meeting we broke the tie between kids and infants (infant come before kids)

Feedback/messaging medium

$\begin{array}{rrrrr}\text { WEIGHT } & \text { SMS } & \text { Sound } & \text { Lights } & \text { Poster } \\ 4 & 4 & 28 & 4 & 4 \\ 3 & 3 & 0 & 15 & 12 \\ 2 & 2 & 6 & 4 & 8 \\ 1 & 6 & 0 & 2 & 1 \\ \text { SUM } & \mathbf{1 5} & \mathbf{3 4} & \mathbf{2 5} & \mathbf{2 5}\end{array}$

During the group meeting we broke the tie between poster and lights (poster comes first) What exclusive use of LPG would require

Continued fuel supply, no questions asked

Group discussion prototyping outcome for the feedback piece:

A sound system combined with an interactive poster (Sound+Poster) 